\title{
Modeling and Computationally Efficient Algorithms for Analysis of Battery Equalization Systems
}

Chen Zhou

chen.2.zhou@uconn.edu

\section{Recommended Citation}

Zhou, Chen, "Modeling and Computationally Efficient Algorithms for Analysis of Battery Equalization Systems" (2016). Master's Theses. 922.

https://opencommons.uconn.edu/gs_theses/922

This work is brought to you for free and open access by the University of Connecticut Graduate School at OpenCommons@UConn. It has been accepted for inclusion in Master's Theses by an authorized administrator of OpenCommons@UConn. For more information, please contact opencommons@uconn.edu. 


\title{
Modeling and Computationally Efficient Algorithms for Analysis of Battery Equalization Systems
}

\author{
Chen Zhou
}

B.E., Xi'an Jiaotong University, 2014

\author{
A Thesis \\ Submitted in Partial Fulfillment of the \\ Requirements for the Degree of \\ Master of Science \\ At the \\ University of Connecticut
}

2016 


\title{
APPROVAL PAGE
}

\author{
Masters of Science Thesis
}

\section{Modeling and Computationally Efficient Algorithms for Analysis of Battery Equalization Systems}

\author{
Presented by \\ Chen Zhou, B.S. \\ Major Advisor \\ Liang Zhang \\ Associate Advisor \\ Ashwin Dani \\ Associate Advisor \\ Peng Zhang
}

University of Connecticut

2016 


\section{TABLE OF CONTENTS}

1. Introduction . . . . . . . . . . . . . . . . . . . . . . 1

1.1 Background ............................ 1

1.2 Organization of Thesis $\ldots \ldots \ldots \ldots \ldots$

1.3 Publications .......................... 7

2. Problem Formulation . . . . . . . . . . . . . . . . . . . . . . . . . . . . . . . . 8

$2.1 \quad$ Structure model . . . . . . . . . . . . . . . . . . . 8

2.2 Modeling Assumptions . . . . . . . . . . . . . . . . . . . . . . 9

2.2.1 Series-based equalization structure . . . . . . . . . . . . . 9

2.2.2 Layer-based equalization structure . . . . . . . . . . . . . . . 10

2.2.3 Module-based equalization structure . . . . . . . . . . . . . . . 12

2.3 Problem Formulation $\ldots \ldots \ldots$. . . . . . . . . . . . . . . . . . . .

2.3.1 Mathematical modeling . . . . . . . . . . . . . . . 13

2.3.2 SOCs approximation problem .................. 14

2.3.3 Equalization time calculation problem ............. 15

2.4 Review of prior result $\ldots \ldots \ldots \ldots \ldots$

2.4.1 Algorithm for approximation of SOC during equalization process for series-based battery equalization system . . . . . . . . 17

2.4.2 Calculation of equalization time for series-based battery equalization system .......................... 19 
3. Layer-Based Equalization Structure . . . . . . . . . . . . . . . . . . . 20

3.1 Mathematical model . . . . . . . . . . . . . . 20

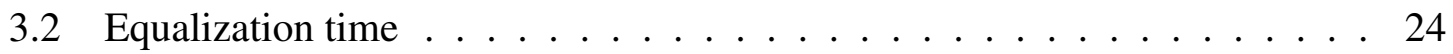

3.2.1 Calculation formula . . . . . . . . . . . . . . 24

3.2.2 Validation by simulation . . . . . . . . . . . . . 24

3.3 Approximation of cell SOCs during equalization . . . . . . . . 25

3.3.1 Calculation formula . . . . . . . . . . . . 25

3.3.2 Validation by simulation . . . . . . . . . . . . 28

3.4 System performance evaluation with external charging/discharging . . . . . 30

4. Module-Based Equalization Structure . . . . . . . . . . . . . . . . . . . 34

4.1 Mathematical model . . . . . . . . . . . . . . 34

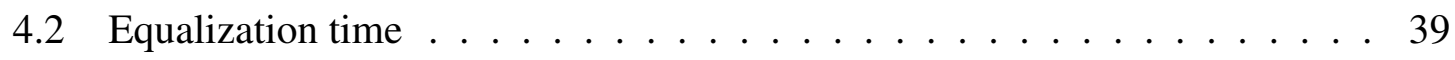

4.2.1 Calculation algorithm . . . . . . . . . . . . . . 39

4.2.2 Validation by simulation ................... 41

4.3 Approximation of cell SOCs during equalization $\ldots \ldots . \ldots 43$

4.3.1 Calculation formula . . . . . . . . . . . . . 43

4.3.2 Validation by simulation .................... 44

4.4 System performance evaluation with external charging/discharging . . . . . 46

5. Comparisons ........................... 50

5.1 Statistical comparison . . . . . . . . . . . . 50 


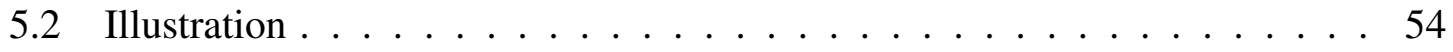

5.3 Comparison of different equalization rate $\ldots \ldots \ldots 7$

6. Conclusions and Future Work . . . . . . . . . . . . . . . . . . . . . . . 62

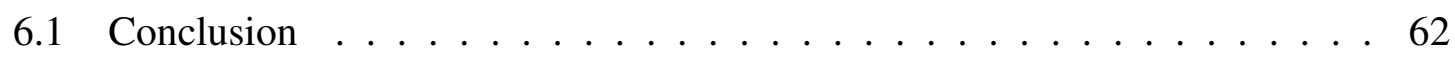

6.2 Future Work . . . . . . . . . . . . . . . . . . 63

$\begin{array}{ll}\text { Bibliography } & 65\end{array}$ 


\section{LIST OF FIGURES}

1.1 Illustration of a 4-cell battery system . . . . . . . . . . . . . 2

1.2 Circuit design and analysis of individual cell equalization [1] . . . . . . 3

1.3 Discharging curves of ten Li-ion cells using a discharging current of 4A [2] 5

2.1 Series-, layer- and module-based equalization system . . . . . . . . . 9

3.1 Layer-based battery equalization system with $B=8 \ldots \ldots$. . . . . 20

3.2 Equalization process of an 8-cell layer-based battery equalization system . . 30

3.3 Equalization process of layer-based system with charging/discharging . . . 33

4.1 Module-based battery equalization system with $B=9 \ldots \ldots$

4.2 Equalization process of a 9-cell module-based battery equalization system . 47

4.3 Equalization process of module-based system with charging/discharging . . 49

5.1 Battery equalization processes under two structures in Example 1 . . . . . 55

5.2 Battery equalization processes under two structures in Example 2 . . . . . 56 


\section{LIST OF TABLES}

3.1 Average approximation error of equalization time under layer-based structure 26

3.2 Average approximation error of cell SOCs under layer-based structure . . . 28

4.1 Average approximation error of equalization time under module-based struc-

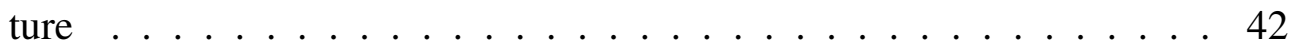

4.2 Average approximation error of cell SOCs under module-based structure . . 45

5.1 Average equalization time in three structures $(\mathrm{B}=8) \ldots \ldots \ldots$. . . . . 51

5.2 Percentage of shortest equalization time for three structures $(B=8) \ldots \ldots 1$

5.3 Average equalization time in three structures $(\mathrm{B}=16) \ldots \ldots \ldots$

5.4 Percentage of shortest equalization time for three structures $(B=16) \quad \ldots \quad$. 51

5.5 Average equalization time in three structures $(\mathrm{B}=32) \ldots \ldots$. . . . . . 52

5.6 Percentage of shortest equalization time for three structures $(B=32) \ldots \ldots 2$

5.7 Average equalization time inthree structures $(\mathrm{B}=64) \ldots \ldots$. . . . . . 52

5.8 Percentage of shortest equalization time for three structures $(B=64) \ldots \ldots 2$

5.9 Average equalization time in layer structure changing equalization rate in one layer $(\mathrm{B}=8) \ldots \ldots \ldots \ldots \ldots \ldots$

5.10 Average equalization time in layer structure changing equalization rate in one layer $(\mathrm{B}=16) \ldots \ldots \ldots \ldots$. . . . . . . . . . . . . . . . 57 
5.11 Average equalization time in layer structure changing equalization rate in one layer $(\mathrm{B}=32) \quad \ldots \ldots \ldots \ldots \ldots \ldots$

5.12 Average equalization time in layer structure changing equalization rate in one layer $(\mathrm{B}=64) \quad \ldots \ldots \ldots \ldots$

5.13 Average equalization time in module structure with different equalization $\operatorname{rate}(\mathrm{B}=8) \ldots \ldots \ldots \ldots \ldots \ldots \ldots$

5.14 Average equalization time in module structure with different equalization

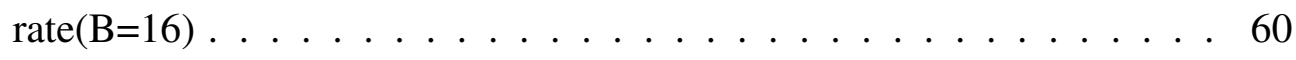

5.15 Average equalization time in module structure with different equalization

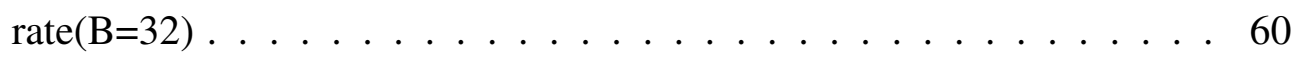

5.16 Average equalization time in module structure with different equalization

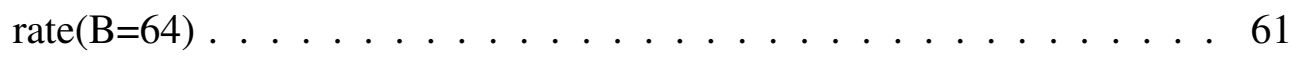




\section{Chapter 1}

\section{Introduction}

\subsection{Background}

The use of battery technology is soaring in various applications such as electronics, space power, electric and hybrid electric vehicles. Indeed, the battery is regarded as one of the most important components for energy storage in autonomous electric systems [3-5]. Since a single cell can only offer limited capacity, multiple battery cells are often connected in series and/or in parallel to meet voltage and current requirements. However, due to manufacturing precision, operating condition variability and other internal and external reasons [6-9], individual cells in a real battery stack typically exhibit variations in performance, for example, amounts of charge held. As a result, charge imbalance among the cells in a battery string becomes a very common issue. Maintaining the charge balance is of critical importance to the performance and life of a battery system $[10,11]$. Indeed, the capacity of the battery string will decrease quickly under charge imbalance, which may lead to lower efficiency or even failure of the entire system [8]. Fig 1.1 in paper [12] gives us a 4-cell battery system for exam- 
ple. In the Fig 1.1, the horizontal axis is time and vertical axis is cell SOC (state of charge, which is defined as the ratio of current charge and charge capacity). Fig 1.1(a) shows the charging process without cell charge equalization. As the time goes on, the four cells' SOCs are increasing and only $b_{4}$ can be fully charged. However, due to the imbalance of initial cell SOC, the other three cells are still under-charged. In Fig 1.1(b), only equalization is presented without charging or discharging. In Fig 1.1(c), when both charging and equalization run simultaneously, the SOCs of all the cells are equalized at the same time as that in Fig 1.1(b), also, as time goes on, all cells can be fully charged.

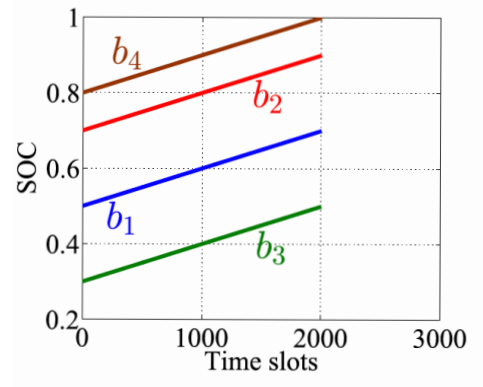

(a)

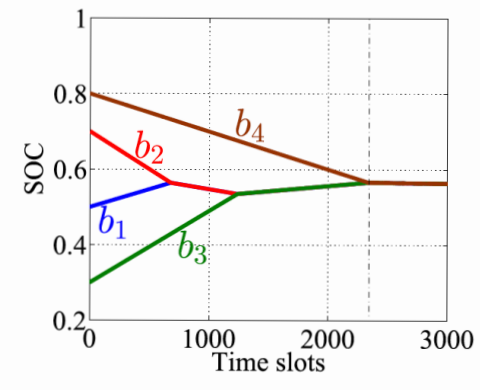

(b)

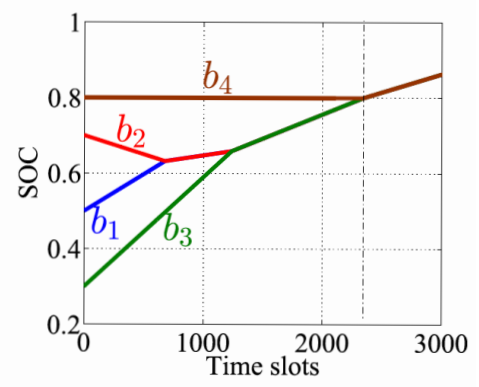

(c)

Fig. 1.1: Illustration of a 4-cell battery system with $x_{1}(0), x_{2}(0), x_{3}(0), x_{4}(0)=$ 0.5,0.7,0.3,0.8. (a) Charging process without equalization. (b) Equalization process without charging and discharging. (c) Simultaneous charging and equalization processes. [12]

To maintain the charge balance in a battery system, special circuit modules are usually designed and connected with the cells. These modules are typically referred 
to as equalizers. Technologies used in the hardware realization of battery equalizers include dissipative resistance shunt [13], bidirectional dc-dc converters [14,15], switch capacitors [16-18], multi winding transformers [19] and two-step buck boost converters [20]. To illustrate the typical analysis performen of equalizer, the circuit diagram studied in paper [1] is given in Fig 1.2. Obviously, the equalizer has a symmetrical structure, therefore, without loss of generality, we assume the SOC of Cell 1 is larger than that of Cell 2. The circuit is driven by PWM(Pulse Width Modulation) signal which controls MOSFET(metal oxide semiconductor field-effect transistor) Q1 to be on and off.

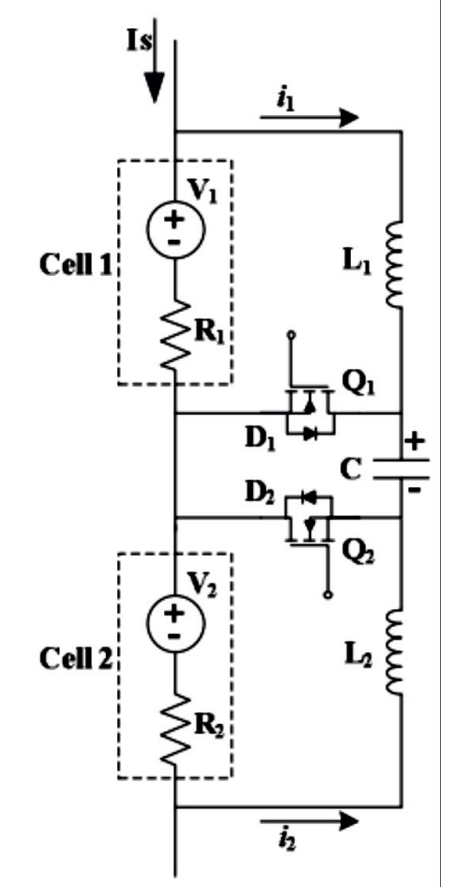

Fig. 1.2: Circuit design and analysis of individual cell equalization [1]

The equalization method can be categorized as passive and active balancing 
[21-27]. In passive equalization, excess charge from higher charged cells are released through resistive elements until all cells reach the same state. On the other hand, in active equalization, charges from higher charged cells are transfered to lower charged cells using energy storage components such as capacitors and inductors [28]. Moreover, for active equalization, appropriate equalization algorithms are also required to maximize efficiency of battery equalization system. The equalization algorithms can be divided into two categories [29, 30]: voltage-based and SOC-based equalization algorithms. Voltage-based equalization algorithms are widely used in real-time systems because of direct measure of cell voltage [31]. SOC-based equalization algorithms typically require accurate knowledge about the remaining capacity in each cell and are more suitable for Li-ion batteries, where a small voltage variation may results in large capacity inconsistency $[32,33]$. For Li-ion battery, the steady-state open circuit voltage, state of charge (SOC), and state of discharge (SOD), all have one-to-one corresponding relationship are mentioned in [34] as shown in Fig 1.3, Therefore, a Li-ion battery management system can improve the balancing circuit to maintain that the voltage difference between cells does not exceed a certain value, so does control the difference of SOC and SOD within a certain range. That is, balancing problem for an Li-ion battery can be equivalent to a voltage balancing.

Up to today, significant research and development efforts have been spent on the electrical hardware design of battery equalization systems and numerous valuable results have been reported [24,35-39].Among these studies, heuristics-based control and 


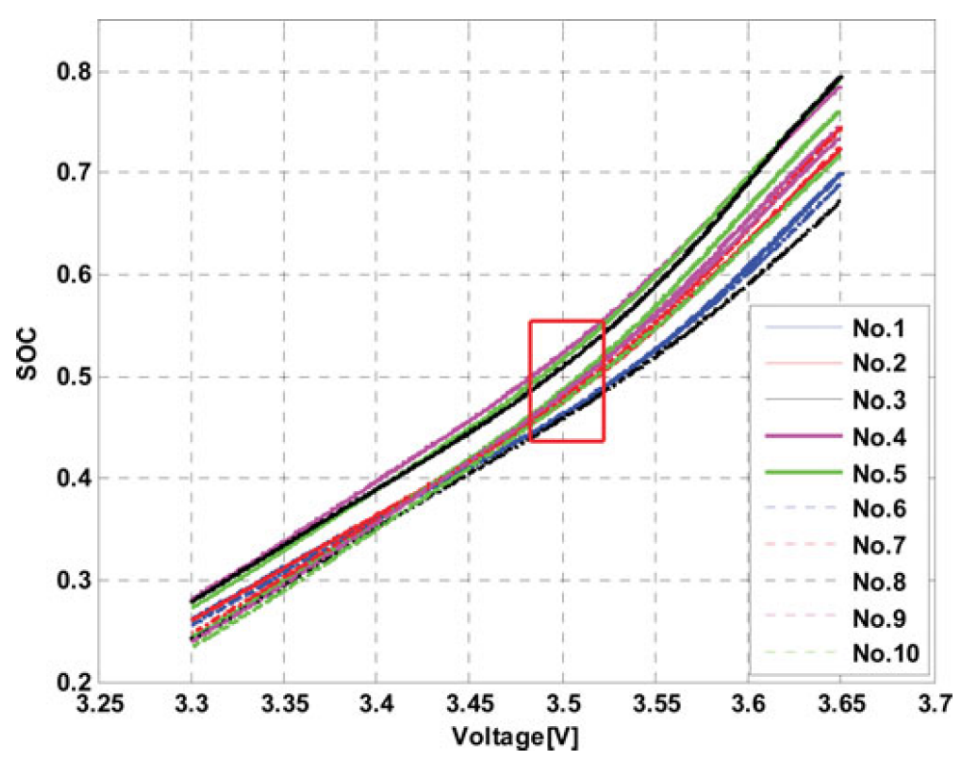

Fig. 1.3: Discharging curves of ten Li-ion cells using a discharging current of 4A [2]

fuzzy logic-based control are discussed in [40], the paper introduce an intelligent battery equalization scheme based on fuzzy logic control is presented to adaptively control the equalizing process of series-connected lithium-ion batteries. The proposed battery equalization scheme is a bidirectional dc-dc converter with energy transferring capacitor that can be used to design the bidirectional nondissipative equalizer for a battery balancing system. Paper [1] is based on the analysis of bi-directional $\mathrm{C} \hat{\mu} \mathrm{k}$ converter, the paper proposed a fuzzy controller to adaptively tune the equalizing current. The inputs of fuzzy controller are selected as the difference in state of charge, the average of state of charge and the total internal resistance. The overall performance of the proposed equalizer is evaluated by multi-indexes such as equalizing speed, efficiency and cell protection. In [41], model predictive control is applied. It should be noted that both 
papers only discuss systems with no more than 4 cells, which is far from practical.

Although significant research have been spent on the electrical hardware design part, meanwhile, limited studies have been carried out to investigate the systems' performances from the system level and a number of questions remain open. For example, given the initial SOC of each battery cell and all the system parameters, how long does it take to complete equalization, charging, and/or discharging? How to predict the SOC of each individual cell at any time instant during the equalization process (with or without charging or discharging)? How to control the process to reduce the equalization time? Seeing the gap in this area, a system-theoretic approach is adopted to study the behavior of battery equalization systems in $[12,42]$. Specifically, paper [42] proposes to a system-level model to describe the charge equalization behavior. Then, analytical algorithms are derived to calculate the equalization time (i.e. the time needed to complete the entire equalization process) for three different types of equalization structures: series-based, layer-based and module-based. The study is extended in [12], which focuses on series-based equalization systems considering energy loss, and external charging/discharging. Moreover, paper [12] also derives algorithms to calculate the SOCs during equalization process. In this paper, we further extend the work of [12] to layer- and module-based equalization systems. 


\subsection{Organization of Thesis}

The remainder of this thesis is organized as follows: Chapter 2 give us the discussion of problem formulations we focus on and introduces the assumption for three structures. Chapter 3 introduces the mathematical model of layer-based battery equalization systems and develops formulas to calculate the time required to complete equalization under given initial cell SOCs, and a computationally efficient algorithm to approximate the cell SOCs during the equalization process. Similar analyses for module-based equalization systems are carried out in chapter 4 . A comparative statistical study of the three equalization structures is carried out in chapter 5. Finally, chapter 6 presents the conclusions and future work.

\subsection{Publications}

Chen Zhou, Liang Zhang, "Modeling and Computationally Efficient Algorithms for Analysis of Battery Equalization Systems", accepted by World Congress on Intelligent Control and Automation Conference, Guilin, China, 2016. 


\section{Chapter 2}

\section{Problem Formulation}

\subsection{Structure model}

In paper [42], three equalization structures are discussed shown in Figure 2.1. In the figure, $b_{i}$ represent battery cells, $e_{j}$ represent equalizers. It is assumed that each equalizer is responsible to balance the two individual cells or two groups of battery cells that are connected with it. For example, in the series-based equalization structure, $e_{i}$ balances $b_{i}$ and $b_{i+1}$ by transferring charge from the cell with higher SOC side to the cell with lower SOC side. In the layer-based equalization structure, for instance, $e_{B / 2+1}$ balance total charge of $b_{1}-b_{2}$ and $b_{3}-b_{4}$, transfer charge from higher SOC side evenly to the lower SOC side. In the module-based equalization structure, we have two kinds of equalizers, cell-level equalizers and module-level equalizers. For example, $e_{1}, e_{2}, \ldots, e_{N-1}, e_{N+1} \ldots$ are cell-level equalizers; $e_{N}, e_{2 N}, \ldots, e_{B-N}$ are modulelevel equalizers. Cell-level equalizers balance two adjacent cells; module-level equalizers balance total SOC between two adjacent modules. 


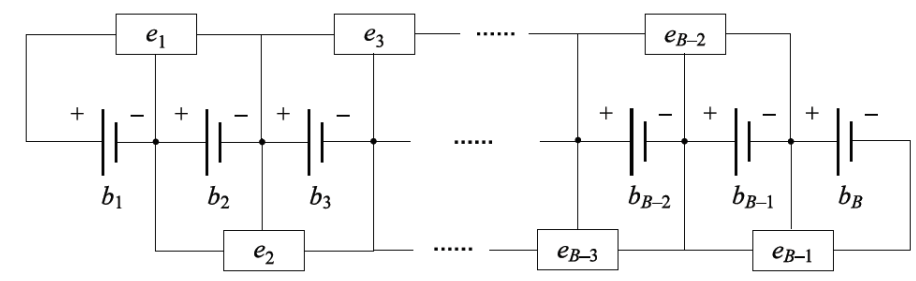

(a) Series-based equalization

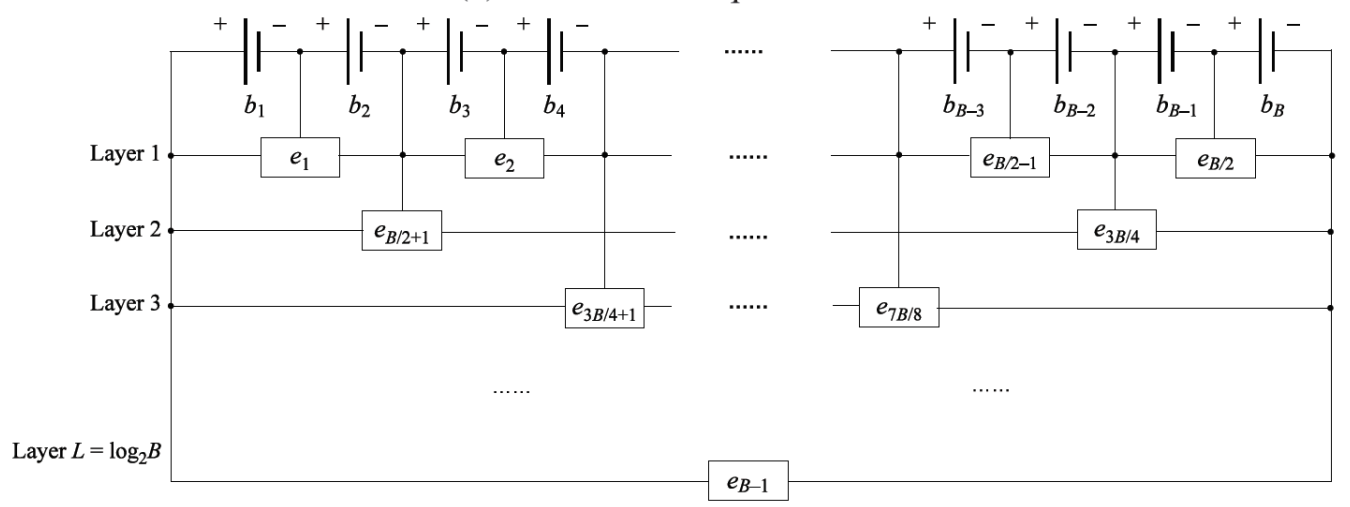

(b) Layer-based equalization

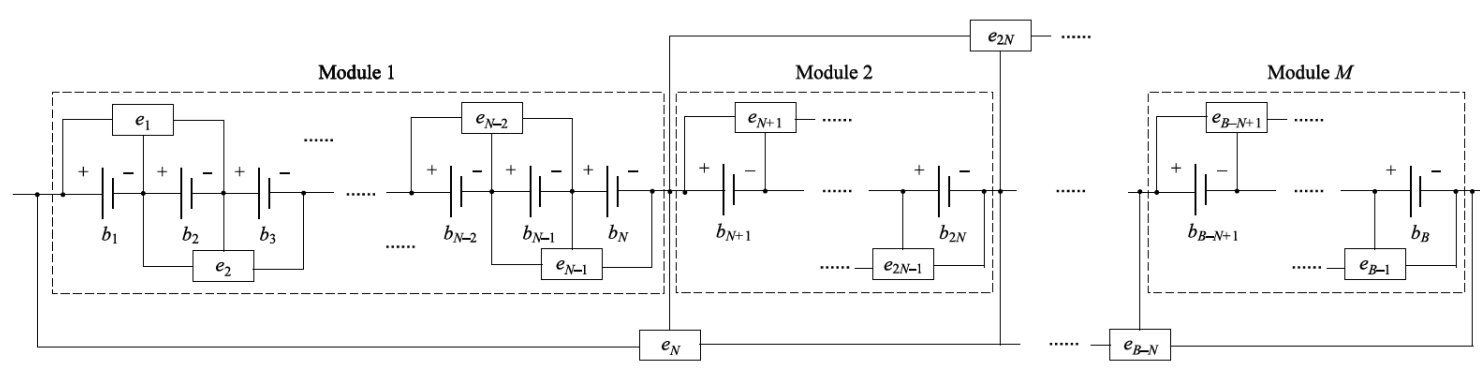

(c) Module-based equalization

Fig. 2.1: Series-, layer- and module-based equalization system

\subsection{Modeling Assumptions}

\subsubsection{Series-based equalization structure}

Consider a battery charge equalization system shown in Figure 2.1(a) defined by the following assumptions.

i The battery system consists of $B$ cells, $b_{1}, b_{2} \ldots b_{B}$, connected in series, and the 
equalization system consists of $B-1$ equalizers, $e_{1}, e_{2}, \ldots e_{B-1}$, connected with every two adjacent cells.

ii All cells have the same capacity. The equalizers have the same working cycle $\tau$. The time axis is slotted with slot duration $\tau$.

iii Each equalizer $e_{i}$ is characterized by its equalization rate, $r_{e, i}$ units of SOC per time slot, and energy loss rate $l_{e, i} \in(0,1), i=1, \ldots, B-1$. For simplicity, assume all the equalizers have identical and constant parameters $r_{e, i}=r_{e}, l_{e, i}=$ $l_{e}$.

iv At the beginning of each time slot, if cell $b_{i}$ have higher SOC than cell $b_{i+1}$, then during this time slot, equalizer $e_{i}$ takes $r_{e}$ units of SOC away from $b_{i}$ with constant rate and sends $\left(1-l_{e}\right) r_{e}$ units of SOC to $b_{i+1}$ also with constant rate. The remaining $l_{e} r_{e}$ units of SOC is consumed by the system as energy loss. Similarly, if cell $b_{i}$ has lower SOC than cell $b_{i+1}$, then equalizer $e_{i}$ takes $r_{e}$ units of SOC away from $b_{i+1}$ and sends $\left(1-l_{e}\right) r_{e}$ units of SOC to $b_{i}$ with the rest $l_{e} r_{e}$ units of SOC consumed as energy loss. If $b_{i}$ and $b_{i+1}$ have equal SOC, then during the time slot no charge transfer takes place between them.

\subsubsection{Layer-based equalization structure}

Consider a layer-based battery equalization structure shown in Figure 2.1(b) based on the following assumptions: 
$\mathrm{i}$ The system consists of $B$ battery cells, $b_{1}, b_{2}, \ldots, b_{B}$ connected in series, and $B-1$ equalizers, $e_{1}, \ldots, e_{B-1}$.

ii Each battery has the same capacity.

iii The equalizers have identical and synchronized working cycle of duration $\tau$ and identical charge loss rate $l_{e}$. In addition, each equalizer $e_{i}$ is characterized by its equalization rate, $r_{i}$ units of SOC per time unit, $i=1, \ldots, B-1$.

iv The equalizers are arranged in $L=\log _{2} B$ layers. In layer $h$, there are $B / 2^{h}$ equalizers. For simplicity, we assume that the equalizers in the same layer have identical equalization rate, denoted as $r_{h}$ for layer $h, h=1, \ldots, L$.

$\mathrm{v}$ Typically, for the cells which can be influenced by equalizer $e_{i}$, we call the cells on the left side of equalizer the left-hand side of it; the cells on the right side of equalizer the right-hand side of it. For instance, the left-side of equalizer $e_{1}$ is $b_{1}$, the right-side of equalizer $e_{1}$ is $b_{2}$. Also, the left-side of equalizer $e_{B /(2+1)}$ is $b_{1}$ and $b_{2}$, the right-side of equalizer $e_{B /(2+1)}$ is $b_{3}$ and $b_{4}$.

vi Each equalizer manages the charge balance between the two substrings of cells connected to its left- and right-hand sides. At layer $h$, such a substring consists of $2^{h-1}$ battery cells. If the total SOC of the cell substring on one side of an equalizer is higher than that on the other side at the beginning of a working cycle, the equalizer removes $r_{h} \tau / 2^{h-1}$ units of SOC from each cell in the substring and transfers $r_{h} \tau\left(1-l_{e}\right) / 2^{h-1}$ units of SOC to each cell in the substring on the other 
side uniformly during this working cycle. Clearly, the total amount of SOC lost during a working cycle $\tau$ is $r_{h} \tau l_{e}$. If the substrings on both sides of an equalizer have the same total SOC, no transfer takes place through this equalizer.

\subsubsection{Module-based equalization structure}

Consider a layer-based battery equalization structure shown in Figure 2.1(c) based on the following assumptions:

i The entire battery series is divided into $M$ modules, each having $N$ cells. Apparently, $B=M \times N$.

ii In such a system, two types of equalizers are present: module-level equalizers and cell-level equalizers.

iii The working cycle for all equalizers are identical (equal to $\tau$ ) and synchronized.

iv Typically, we call the cells within the left side of equalizer which it can affect the left-hand side of the equalizer; the cells within the right side of equalizer which it can affect the right-hand side of the equalizer. For instance, the left-side of equalizer $e_{1}$ is $b_{1}$, the right-side of equalizer $e_{1}$ is $b_{2}$. Also, the left-side of equalizer $e_{N}$ is $b_{1}, b_{2}, \ldots, b_{N}$, the right-side of equalizer $e_{N}$ is $b_{N+1}, b_{N+2}, \ldots, b_{2 N}$.

v A module-level equalizer manages the charge balance between two adjacent modules. Specifically, if the total SOC of the cells in a module is higher than that of a 
neighboring module at the beginning of a working cycle, the associated modulelevel equalizer between the two modules removes $r_{m} / N$ units of SOC from each cell in the module and transfers $r_{m}\left(1-l_{m}\right) / N$ units of SOC to each cell in that neighboring module uniformly during this working cycle. If the two adjacent modules have the same total SOC, no transfer takes place through their associated module-level equalizer. A cell-level equalizer manages the charge balance between two adjacent cells within the same module with equalization rate $r_{c}$ and charge loss rate $l_{c}$.

\subsection{Problem Formulation}

In the thesis, we mainly study about three questions for layer-based and module-based battery equalization system. These three problem have already been solved for seriesbased battery equalization system in paper [12], which we will give a brief discussion in next part.

\subsubsection{Mathematical modeling}

The first problem is to build mathematical model based on the assumptions above. Let $t_{n}=n \tau, n=0,1,2, \ldots$, and denote the $n$-th time slot as $\left[t_{n-1}, t_{n}\right), n>0$. The SOC for each cell at time $t_{n+1}$ can be expressed based on the SOC for each cell at time $t_{n}$ 
using the formulas:

$$
\begin{array}{r}
\mathbf{X}\left(t_{n+1}\right)=f_{\text {series }}\left(\mathbf{X}\left(t_{n}\right), r_{e}, l_{e}\right) \\
\mathbf{X}\left(t_{n+1}\right)=f_{\text {layer }}\left(\mathbf{X}\left(t_{n}\right), r_{h}, l_{e}\right) \\
\mathbf{X}\left(t_{n+1}\right)=f_{\text {module }}\left(\mathbf{X}\left(t_{n}\right), r_{c}, r_{m}, l_{e}\right)
\end{array}
$$

Here, $\mathbf{X}\left(t_{n}\right)=\left[x_{1}\left(t_{n}\right), x_{2}\left(t_{n}\right), \ldots, x_{B}\left(t_{n}\right)\right]$, where $x_{i}\left(t_{n}\right)$ represents SOC of $b_{i}$ at $n$-th time slot. Formulas (2.1), (2.2) and (2.3) are the mathematical modeling for series-, layer- and module-based battery equalization system respectively. According to assumptions, SOCs at $t_{n}$ time slot depend on prior state. For series-based battery equalization system, in addition to SOC for each cell at time $t_{n}$, the SOC for each cell at time $t_{n+1}$ is also based on equalization rate $r_{e}\left(r_{h}\right.$ for layer-based battery equalization system; $r_{c}$ and $r_{m}$ for module-based battery equalization system) and energy loss rate $l_{e}$. In these cases, all three systems have been derived when $l_{e}=0$ in the paper [42]; when $l_{e} \neq 0$, only series-based battery equalization system has been discussed in paper [12]. In the thesis, We mainly focus on the derivation of the equations $f_{\text {layer }}$ and $f_{\text {module }}$.

\subsubsection{SOCs approximation problem}

While formulas (2.1), (2.2) and (2.3) can calculate $X\left(t_{n+1}\right)$ based on $X\left(t_{n}\right)$, it is inefficient since we need to calculate from $X\left(t_{0}\right)$ in order to get $X\left(t_{n+1}\right)$. Also, we need to do calculation for each $\tau$, based on assumptions, $\tau$ is short and the calculation will be so many times during a second. The desirable of the calculation of $X\left(t_{n}\right)$ directly from $X(0)$ similar of mathematical modeling, also possible to calculate $X\left(t_{n}\right)$ from $X(0)$ 
and system parameter, that is:

$$
\begin{array}{r}
\mathbf{X}\left(t_{n}\right)=g_{\text {series }}\left(\mathbf{X}(0), r_{e}, l_{e}\right) \\
\mathbf{X}\left(t_{n}\right)=g_{\text {layer }}\left(\mathbf{X}(0), r_{h}, l_{e}\right) \\
\mathbf{X}\left(t_{n}\right)=g_{\text {module }}\left(\mathbf{X}(0), r_{c}, r_{m}, l_{e}\right)
\end{array}
$$

Formulas (2.4), (2.5) and (2.6) are the approximations of SOCs for series-, layerand module-based battery equalization system respectively. For series-based battery equalization system, in addition to initial SOC state of each cell, the SOC for each cell at time $t_{n+1}$ is also based on equalization rate $r_{e}\left(r_{h}\right.$ for layer-based battery equalization system; $r_{c}$ and $r_{m}$ for module-based battery equalization system) and energy loss rate $l_{e}$.

The approximation of SOCs of series-based battery equalization system has been derived from paper [12], so in the thesis we mainly focus on layer- and module-based battery equalization systems. In the thesis, we will derive the the equation of $g_{\text {layer }}$ and $g_{\text {module }}$

\subsubsection{Equalization time calculation problem}

In addition to the calculation of SOCs, it is also important to calculate system performance in efficient way. $T_{e}$ is defined as the time instant when the SOCs of all cells are

equal assuming that there is no external charging or discharging. Again, $T_{e}$ should be 
function of $X(0)$ and system parameters, which can be expressed as:

$$
\begin{array}{r}
T_{e}=h_{\text {series }}\left(\mathbf{X}(0), r_{e}, l_{e}\right) \\
T_{e}=h_{\text {layer }}\left(\mathbf{X}(0), r_{h}, l_{e}\right) \\
T_{e}=h_{\text {module }}\left(\mathbf{X}(0), r_{c}, r_{m}, l_{e}\right)
\end{array}
$$

Formulas (2.7), (2.8) and (2.9) are the calculation of equalization time for series, layer- and module-based battery equalization system respectively. For series-based battery equalization system, the problem is to derive the formula to calculate the equalization time directly from initial SOC state of each cell $\mathbf{X}(0)$, equalization rate $r_{e}\left(r_{h}\right.$ for layer-based battery equalization system; $r_{c}$ and $r_{m}$ for module-based battery equalization system) and energy loss rate $l_{e}$. In these cases, all have been derived when $l_{e}=0$ in the paper [42]; when $l_{e} \neq 0$, only series-based battery equalization system has been

discussed in paper [12]. In the thesis, we will focus on the the equation of $h_{\text {layer }}$ and $h_{\text {module }}$.

\subsection{Review of prior result}

Paper [42] studies three types of battery equalization system structures: series-based, layer-based and module-based. It also derive mathematical modules that describe the system-level behavior of the battery equalization process under these equalization structures. Then, based on the mathematical models, analytical methods are develop to evaluate the performance of the equalization process. In addition, statistical analysis is 
carried out to compare the performance of the three equalization structures. However, research in paper [42] does not take energy loss during the equalization process into account.

Paper [12] mainly discusses series-based equalization system. It proposes mathematical model for series-connected battery equalization systems, develops an analytical algorithm to approximate the SOC of battery cells at any time instant during the equalization process, and derives the formulas to calculate the time needed to finish equalization process. The discussion in the thesis is based on the study of the approximation of SOC and calculation of equalization time for series-based battery equalization system, here we give a briefly discussion of the approximation of SOC and calculation of equalization time for series-based battery equalization system.

\subsubsection{Algorithm for approximation of SOC during equalization process for series-based battery equalization system}

i Identify all initially active MBGs (MBG is any battery group with the time instant when all cells of $B G(g, i)$ merge together for the first time is smaller than the time instant when $B G(g, i)$ (represent as cell $\left.b_{i}, b_{i+1}, \ldots, b_{i+g-1}\right)$ merges with any neighboring neighboring cell for the first time): For all $i \in\{1, \ldots, B-$ $1\}$, if $x_{i}(0)=x_{i+1}(0)$, then $b_{i}$ and $b_{i+1}$ belong to the same initial active MBG; otherwise, $b_{i}$ and $b_{i+1}$ belong to different initial active MBGs.

ii Calculation the SOC charge rate, $k_{(g, i)}$, for each MBG that is currently active. 
This leads to a linear function of $t$ for each active MBG:

$$
y_{(g, i)}(t)=\bar{x}_{g, i}(0)+\frac{k_{(g, i)}}{g} t
$$

iii Identify the next merging point: For every pair of neighboring MBGs that are currently active, calculate the intersection of the linear functions $t_{g, i}(t)$ 's obtained in Step 2. Specifically, for active neighboring MBGs, $B G\left(g_{1}, i_{1}\right)$ and $B G\left(g_{2}, i_{2}\right)$, their intersection time can be obtained by equation $y_{g_{1}, i_{1}}(t)$ and $y_{g_{2}, i_{2}}(t)$ as follows:

$$
\bar{x}_{g_{1}, i_{1}}(0)+\frac{k_{\left(g_{1}, i_{1}\right)}}{g_{1}} t=\bar{x}_{g_{2}, i_{2}}(0)+\frac{k_{\left(g_{2}, i_{2}\right)}}{g_{2}} t
$$

then,

$$
t=g_{1} g_{2} \frac{\bar{x}_{\left(g_{1}, i_{1}\right)}(0)-\bar{x}_{\left(g_{2}, i_{2}\right)}(0)}{g_{1} k_{\left(g_{2}, i_{2}\right)}-g_{2} k_{\left(g_{1}, i_{1}\right)}}
$$

Among all intersection time, let $t_{m}^{(s)}$ denote the smallest one, which results from merging battery groups $B G\left(g_{1}^{(s)}, i_{1}^{(s)}\right)$ and $B G\left(g_{2}^{(s)}, i_{2}^{(s)}\right)$. Without loss of generality, assume $i_{1}^{(s)}<i_{2}^{(s)}$.

iv Update the active MBGs: After $t=t_{m}^{(s)}$, MBGs $B G\left(g_{1}^{(s)}, i_{1}^{(s)}\right)$ and $B G\left(g_{2}^{(s)}, i_{2}^{(s)}\right)$ identified in step 3 are both deactivated, while their combination, $B G\left(g_{1}^{(s)}+\right.$ $\left.g_{2}^{(s)}, i_{1}^{(s)}\right)$ become an active MBG. Other active MBGs remain active after $t=t_{m}^{(s)}$.

$\mathrm{v}$ For $t>t_{m}^{(s)}$, if there is only one MBG being active, let $S=s$ and stop the algorithm; otherwise, let $s=s+1$ and return to step 2 .

After the algorithm is terminated, we will obtain the locations of all merging points, 
all merging battery groups, and their active periods. Assume cell $b_{j}$ belongs to active merging battery group $B G(g, i)$ at time $t$. Then, the SOC of $b_{j}$ at time $t$ can be approximated as :

$$
\hat{x}_{j}(t)=\bar{x}_{(g, i)}(0)+\frac{k_{(g, i)}}{g} t, \quad i \leq j \leq i+g-1
$$

\subsubsection{Calculation of equalization time for series-based battery equalization system}

In the approximated equalization process generated above, the approximated equalization time $\hat{T}_{e}$ can be directly calculated by:

$$
\widehat{T}_{e}=\max _{g \in\{1, \ldots, B-1\}} t_{\text {ideal }}(g, 1)
$$

where

$$
\begin{aligned}
& t_{\text {ideal }}(g, i)=\left\{\begin{array}{l}
\frac{\left(\bar{x}_{(g, i)}(0)-\bar{x}_{(B, 1)}(0)\right) \tau}{-\left(\left(\frac{1}{g}-\frac{1}{B}\right) l_{e}-\frac{\rho_{(g, i)}}{g}\right) r_{e}}, \\
\frac{\left(\bar{x}_{(g, i)}(0)-\bar{x}_{(B, 1)}(0)\right) \tau}{-\left(\left(\frac{1}{g}-\frac{1}{B}\right) l_{e}+\frac{\rho_{(g, i)}\left(1-l_{e}\right)}{g}\right) r_{e}},
\end{array} \quad \text { if } \quad \bar{x}_{(g, i)}(0)>\bar{x}_{(B, 1)}(0)<\bar{x}_{(B, 1)}(0)\right. \\
& g \in\{1, \ldots, B-1\}, i \in\{1, \ldots, B-g+1\} .
\end{aligned}
$$

The results described in Section 2.4.1 and 2.4.2 will be used in the thesis to approximate SOCs and calculate equalization time for module-based battery equalization system respectively. 


\section{Chapter 3}

\section{Layer-Based Equalization Structure}

\subsection{Mathematical model}

Based on the assumptions we presented in the previous chapter, an 8-cell layer-based battery equalization system is shown in Figure 3.1. This system has $L=3$ layers and

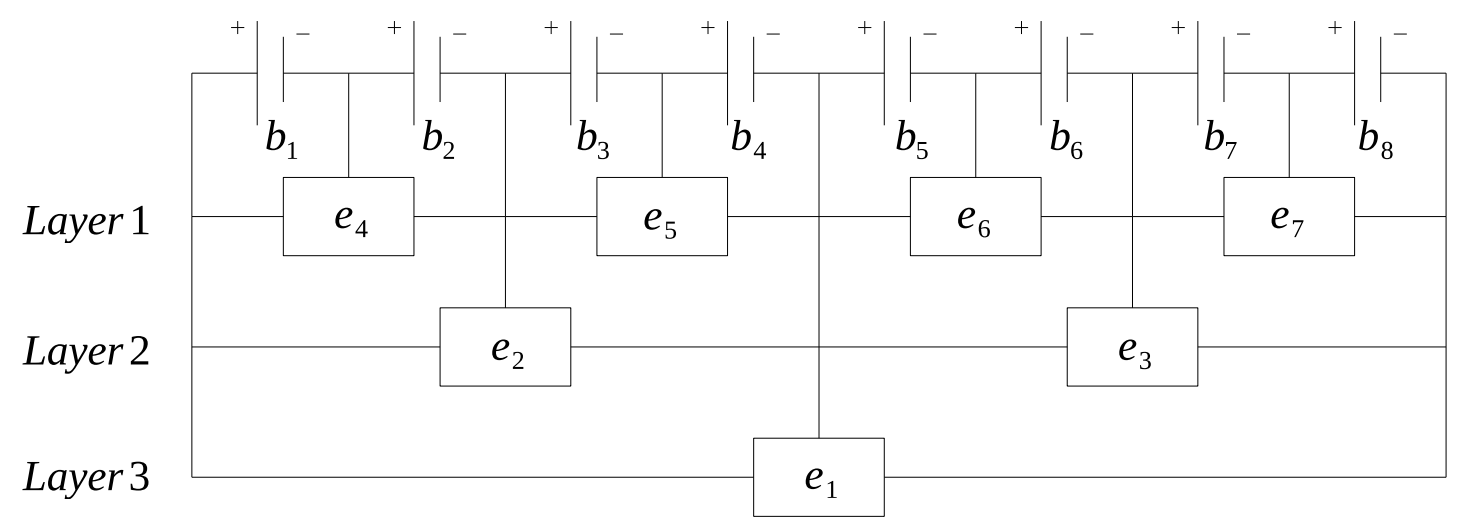

Fig. 3.1: Layer-based battery equalization system with $B=8$

each equalizer manages two substrings. For instance, equalizer $e_{3}$ manages substring $b_{5}-b_{6}$ (left of $e_{3}$ ) and substring $b_{7}-b_{8}$ (right of $e_{3}$ ), while $e_{1}$ manages $b_{1}-b_{2}-b_{3}-b_{4}$ and $b_{5}-$ $b_{6}-b_{7}-b_{8}$. On the other hand, each cell is affected by the operation of $L=3$ equalizers - one from each layer. For instance, cell $b_{4}$ is affected by $e_{1}, e_{2}$, and $e_{5}$. Moreover, 
since each equalizer treats each cell in a substring evenly, the equalization operation of one equalizer is independent of all others in the system.

In a $B$-cell layer-based battery equalization system, the $i$-th battery is affected by equalizers $\left[\frac{i+B-1}{2^{1}}\right],\left[\frac{i+B-1}{2^{2}}\right], \ldots,\left[\frac{i+B-1}{2^{L}}\right]$. For the $j$-th equalizer in layer $h$, let $S_{h, j}^{+}$and $S_{h, j}^{-}$represent the sets of battery cells that are on the left-hand side and the right-hand side of this equalizer, respectively. According to the model assumptions, we have

$$
\begin{gathered}
S_{h, j}^{+}=\left\{(j-1) 2^{h}+1,(j-1) 2^{h}+2, \ldots,(j-1) 2^{h}+2^{h-1}\right\}, \\
S_{h, j}^{-}=\left\{(2 j-1) 2^{h}+1,(2 j-1) 2^{h}+2, \ldots,(2 j-1) 2^{h}+2^{h-1}\right\} .
\end{gathered}
$$

Let $\Delta_{h, j}\left(t_{n}\right)$ denotes the total SOC difference between these two substrings. Then,

$$
\Delta_{h, j}\left(t_{n}\right)=\sum_{m \in S_{h, j}^{-}} x_{m}\left(t_{n}\right)-\sum_{m \in S_{h, j}^{+}} x_{m}\left(t_{n}\right) .
$$

To determine the charge transfer between these two substrings through this equalizer, introduce

$$
\operatorname{sgn}\left(v, l_{e}\right)= \begin{cases}-1, & v<0 \\ 0, & v=0 \\ 1-l_{e}, & v>0 .\end{cases}
$$

Thus, $\operatorname{sgn}\left(\Delta_{h, j}\left(t_{n}\right), l_{e}\right)$ represents the proportion of charges transferred to/from each substring. Next, to determine whether battery $i$ belongs to any of these two substrings, 
the indicator function can be used:

$$
I_{A}(x)= \begin{cases}1, & x \in A \\ 0, & \text { otherwise }\end{cases}
$$

Clearly, if $I_{S_{h, j}^{+}}(i)=I_{S_{h, j}^{-}}(i)=0$, the equalizer have no influence to battery $i$; if $I_{S_{h, j}^{+}}(i)=1, I_{S_{h, j}^{-}}(i)=0$, the battery $i$ is on the left-hand side of the equalizer; if $I_{S_{h, j}^{+}}(i)=0, I_{S_{h, j}^{-}}(i)=1$, the battery $i$ is on the right-hand side of the equalizer. The charge transfer scenarios for each of these three cases are described below:

i When $i \notin S_{h, j}^{+}$and $i \notin S_{h, j}^{-}$, in this case, the $j$-th equalizer in the $h$-th layer does not contribute to $b_{i}$ and no charge transfer occurs in $b_{i}$ due to this equalizer.

ii When $i \in S_{h, j}^{+}$, there are three possibilities in this case:

(a) When $\Delta_{h, j}\left(t_{n}\right)>0$, the total charge of the substring on the right-hand side of $j$-th equalizer in layer $h$ is larger than that on the left-hand side. Under this situation, the cells within $S_{h, j}^{+}$receive a total of $\left(1-l_{e}\right) r_{h}$ units of charge during this time slot, which is evenly distributed to each one, i.e., $\frac{\left(1-l_{e}\right) r_{h}}{2^{h-1}}$ per cell. On the other hand, the cells within $S_{h, j}^{-}$lose a total of $r_{h}$ units of charge during this time slot, which is also evenly distributed to each one, i.e., $\frac{r_{h}}{2^{h-1}}$ for each cell.

(b) When $\Delta_{h, j}\left(t_{n}\right)<0$, the total charge of the substring on the left-hand side of $j$-th equalizer in layer $h$ is larger than that on the right-hand side. Under this situation, the cells within $S_{h, j}^{-}$receive a total of $\left(1-l_{e}\right) r_{h}$ units of charge 
during this time slot, which is evenly distributed to each one, i.e., $\frac{\left(1-l_{e}\right) r_{h}}{2^{h-1}}$ per cell. On the other hand, the cells within $S_{h, j}^{+}$lose a total of $r_{h}$ units of charge during this time slot, which is also evenly distributed to each one, i.e., $\frac{r_{h}}{2^{h-1}}$ for each cell.

(c) When $\Delta_{h, j}\left(t_{n}\right)=0$, the total charge of the substring on the left-hand side of $j$-th equalizer in layer $h$ is as same as that on the right-hand side.Under this situation, no charge transferred.

iii When $i \in S_{h, j}^{-}$, there are three possibilities in this case which are similar to part (b).

To distinguish these three cases, for case $1, I_{S_{h, j}^{+}}(i)=I_{S_{h, j}^{-}}(i)=0$; for case 2, $I_{S_{h, j}^{+}}(i)-I_{S_{h, j}^{-}}(i)=1$; for case $3, I_{S_{h, j}^{+}}(i)-I_{S_{h, j}^{-}}(i)=-1$.

Let $t_{n}=n \tau, n=0,1,2, \ldots$, and let $x_{i}(t) \in[0,1], i=1, \ldots, B$, denote the SOC of cell $b_{i}$ at time $t \geq 0$. Then, based on the discussion above, the evolution of the cell SOCs' are given by

$$
x_{i}(t)=x_{i}\left(t_{n}\right)+k_{i}\left(t_{n}\right)\left(t-t_{n}\right), t \in\left(t_{n}, t_{n+1}\right], n=0,1, \ldots,
$$

where $k_{i}\left(t_{n}\right)$ is the total charge transfer rate at cell $b_{i}$ from all equalizers during time

$$
\begin{aligned}
& \left(t_{n}, t_{n+1}\right]: \\
& k_{i}\left(t_{n}\right)=\sum_{h=1}^{L} \sum_{j=1}^{B / 2^{h}}\left(\operatorname{sgn}\left(\Delta_{h, j}\left(t_{n}\right), l_{e}\right) \cdot\left[I_{S_{h, j}^{+}}(i)-I_{S_{h, j}^{-}}(i)\right] \cdot \frac{r_{h}}{2^{h-1}}\right), \quad i=1, \ldots, B .
\end{aligned}
$$




\subsection{Equalization time}

\subsubsection{Calculation formula}

In each time unit, the equalizer remove $r_{h}$ units of charge from the higher SOC side and transfer $r_{h}\left(1-l_{e}\right)$ units of charges to the lower SOC side. Since the equalizers in the layer-based structure work independently of each other, the time needed for $e_{i}$ to balance the charge of its two associated substrings is

$$
t_{e q}(i)=\frac{\left|\Delta_{h(i), j(i)}(0)\right|}{\left(r_{h}+\left(1-l_{e}\right) r_{h}\right)},
$$

where

$$
h(i)=L-\left\lfloor\log _{2} i\right\rfloor, \quad j(i)=i-2^{L-h(i)}+1 .
$$

In the equation, $\left|\Delta_{h(i), j(i)}(0)\right|$ is absolute difference between two sides of equalizer. Note that, in each time slot, the equalizer remove $r_{h}$ units of charge from the higher SOC side and transfer $r_{h}\left(1-l_{e}\right)$ units of charges to the lower SOC side.

Then, the time for all cells in the system to achieve equalization, denoted as $\widehat{T}_{e}^{\text {layer }}$, can be calculated by

$$
\widehat{T}_{e}^{\text {layer }}=\max _{i \in\{1, \ldots, B-1\}} t_{e q}(i)
$$

\subsubsection{Validation by simulation}

In order to justify the accuracy of equation (3.8), a MATLAB program is created to "simulate" the system behavior based on the mathematical model defined by the as- 
sumptions above, i.e., by iteratively calculating the values of $x_{i}\left(t_{n}\right)$ based on equation (3.4). To carry out the numerical experiments, we run the program on systems with the number of cells ranging from $B \in\{4,8,16,32\}$, the equalization rate from $r_{h} \in\left\{10^{-4}, 10^{-5}, 10^{-6}\right\}$ and $l_{e}=0.1$. For each combination of $B$ and $r_{h}, 5000$ samples are tested with initial SOCs randomly and independently generated from uniform distribution $U(0,1)$. For each sample, we evaluate its true equalization time $T_{e}^{\text {layer }}$ from simulation and compare it with $\widehat{T}_{e}^{\text {layer }}$ calculated based on equations (3.6)-(3.8). The accuracy is evaluated using the percentage error between the two values:

$$
\epsilon_{e}=\frac{\left|T_{e}^{\text {layer }}-\widehat{T}_{e}^{\text {layer }}\right|}{T_{e}^{\text {layer }}} \cdot 100 \% .
$$

The results are summarized in Table 3.1. As we can see, the average error $\bar{\epsilon}_{e}$ is very small for all cases studied, which implies that the calculated equalization time is close to the true value. Therefore, we claim that equations (3.6)-(3.8) can be used to calculate the equalization time for layer-based battery equalization systems.

\subsection{Approximation of cell SOCs during equalization}

\subsubsection{Calculation formula}

While the cell SOCs of the battery equalization system considered in this chapter can be calculated based on equation (3.4), the computational time may be overly long for small $r_{h}$ due to iterative calculation of $x_{i}\left(t_{n}\right)$ for every single $n=0,1,2, \ldots$ To overcome this problem, note that each cell is affected by exactly $L$ equalizers - one from each 
Table 3.1: Average approximation error of equalization time under layer-based structure

\begin{tabular}{|cccc|}
\hline$r_{e}$ & $10^{-4}$ & $10^{-5}$ & $10^{-6}$ \\
\hline $\bar{\epsilon}_{e}(4)$ & $0.0126 \%$ & $0.0014 \%$ & $0.0002 \%$ \\
$\bar{\epsilon}_{e}(8)$ & $0.0569 \%$ & $0.0058 \%$ & $0.0006 \%$ \\
$\bar{\epsilon}_{e}(16)$ & $0.1106 \%$ & $0.0128 \%$ & $0.0014 \%$ \\
$\bar{\epsilon}_{e}(32)$ & $0.2989 \%$ & $0.0307 \%$ & $0.0033 \%$ \\
\hline
\end{tabular}

layer, and that each equalizer transfers charge into or out of a cell with constant rate before equalization is reached. Moreover, the total operating time of each equalizer can be calculated using (3.6). During the equalization process, each equalizer have two state: either still equalizing charge between the cells or finish equalization process. Since in the layer-based structure, each equalizer works independently, it is possible to calculate the equalization time for each equalizer. Then we can determine whether each equalizer is still operating at given time $t$ :

i If $t \geq t_{e q}(i)$, which means the equalizer $i$ has stop working at time t. In this case, $I_{\left\{u \mid u \geq t_{e q}\left(i_{h}\right)\right\}}(t)=1$ and $I_{\left\{u \mid u<t_{e q}\left(i_{h}\right)\right\}}(t)=0$. Let $i_{h}$ denotes the index of the equalizer in layer $h$ which have affect on battery $i$. By the time $e_{i_{h}}$ stop working, considering the energy loss during the process, $e_{i_{h}}$ contribute $\frac{\Delta_{h, j\left(i_{h}\right)} \cdot\left[I_{S_{h, j}^{+}}(i)-I_{S_{h, j}^{-}}(i)\right]-r_{h} l_{e} t_{e q}(i)}{2}$ to each side, apparently, the contribution of $e_{i_{h}}$ is larger than 0 for the lower SOC side and smaller than 0 for the higher SOC 
side. For the time after $t_{e q}(t)$, when $e_{i}$ stop working, the total energy loss is $r_{h} l_{e}\left(t-t_{e q}(i)\right)$ taken by the two sides evenly, that is $\frac{r_{h} l_{e}\left(t-t_{e q}(i)\right)}{2}$ for each side. Combining the time before and after the equalizer's equalization time, we can

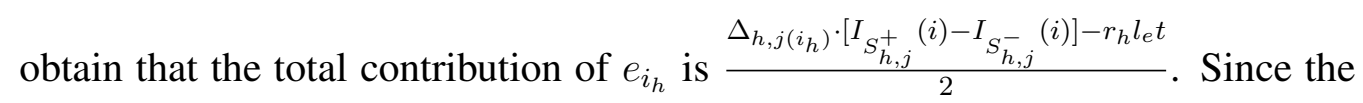
equalizer removes or transfers charge evenly from one side to the other, we can obtain that $e_{i_{h}}$ contributes $\frac{\Delta_{h, j\left(i_{h}\right)} \cdot\left[I_{S_{h, j}^{+}}(i)-I_{S_{h, j}^{-}}(i)\right]-r_{h} l_{e} t}{2^{h}}$ to each cell.

ii If $t<t_{e q}(i)$, which means the equalizer $i$ has not stopped working at time $t$. In this case, $I_{\left\{u \mid u \geq t_{e q}\left(i_{h}\right)\right\}}(t)=0$ and $I_{\left\{u \mid u<t_{e q}\left(i_{h}\right)\right\}}(t)=1$. $e_{i_{h}}$ removes $r_{h} t$ units of SOCs evenly from the higher SOC side and transfers $r_{h} t\left(1-l_{e}\right)$ units of SOCs evenly to the lower SOC side. That is, for the equalizer in layer $h$, each cell in the higher SOC side removes $\frac{r_{h} t}{2^{h-1}}$, each cell in the lower SOC side receive $\frac{r_{h} t\left(1-l_{e}\right)}{2^{h-1}}$.

We can get the approximation SOC of $b_{i}$ at time $t$ by combining the two cases discussed above:

$$
\begin{aligned}
\widehat{x}_{i}(t)=x_{i}(0) & +\sum_{h=1}^{L} I_{\left\{u \mid u \geq t_{e q}\left(i_{h}\right)\right\}}(t) \cdot \frac{\Delta_{h, j\left(i_{h}\right)} \cdot\left[I_{S_{h, j}^{+}}(i)-I_{S_{h, j}^{-}}(i)\right]-r_{h} l_{e} t}{2^{h}} \\
& +\sum_{h=1}^{L} I_{\left\{u \mid u<t_{e q}\left(i_{h}\right)\right\}}(t) \cdot \operatorname{sgn}\left(\Delta_{h, j\left(i_{h}\right)}(0), l_{e}\right) \cdot t \cdot r_{h} \cdot \frac{\left[I_{S_{h, j}^{+}}(i)-I_{S_{h, j}^{-}}(i)\right]}{2^{h-1}},
\end{aligned}
$$

where $i_{h}$ is the index of the equalizer in layer $h$ that affects battery $b_{i}$ given by

$$
i_{h}=\left\lfloor\frac{i+B-1}{2^{h}}\right\rfloor,
$$

and $j(\cdot)$ is defined in (3.7). In equation (3.10), $x_{i}(0)$ is the initial SOC of battery $i, i_{h}$ represents the index of equalizer in layer $h$ which can influence $b_{i}$. 


\subsubsection{Validation by simulation}

In order to test the accuracy of equation (3.10), the same simulation program and the same data set generated above are used. For each sample, we first simulate the system by iteratively calculating the values for all $x_{i}\left(t_{n}\right)$ 's until all cells are equalized. Then, the approximated SOCs $\widehat{x}_{i}\left(t_{n}\right)$ are calculated based on equation (3.10). The accuracy of the method is evaluated based on:

$$
\epsilon_{S O C}=\frac{\sum_{i=1}^{B} \sum_{n=0}^{\left\lfloor T_{e} / \tau\right\rfloor} \frac{\left|\widehat{x}_{i}\left(t_{n}\right)-x_{i}\left(t_{n}\right)\right|}{x_{i}\left(t_{n}\right)}}{B\left(\left\lfloor T_{e} / \tau\right\rfloor+1\right)} \cdot 100 \%
$$

The results are summarized in Table 3.2. As one can see, the average error $\bar{\epsilon}_{S O C}(B)$ is again very small. What's more, as equalization rate for equalizer reduce by 10 times, $\bar{\epsilon}_{S O C}(B)$ also reduce by 10 times. Therefore, we claim that equation (3.10) can be used to approximate the cell SOCs for the battery system during the equalization process.

Table 3.2: Average approximation error of cell SOCs under layer-based structure

\begin{tabular}{|cccc|}
\hline$r_{e}$ & $10^{-4}$ & $10^{-5}$ & $10^{-6}$ \\
\hline $\bar{\epsilon}_{S O C}(4)$ & $0.0399 \%$ & $0.0040 \%$ & $0.0004 \%$ \\
$\bar{\epsilon}_{S O C}(8)$ & $0.0442 \%$ & $0.0044 \%$ & $0.0004 \%$ \\
$\bar{\epsilon}_{S O C}(16)$ & $0.0510 \%$ & $0.0051 \%$ & $0.0005 \%$ \\
$\bar{\epsilon}_{S O C}(32)$ & $0.0518 \%$ & $0.0052 \%$ & $0.0005 \%$ \\
\hline
\end{tabular}

As an illustration, consider a layer-based battery equalization system with parameters $B=8, r_{h}=10^{-4}, l_{e}=0.1$. The initial SOCs of the cells are $x_{1}(0)=0.1104$, 
$x_{2}(0)=0.3968, x_{3}(0)=0.2242, x_{4}(0)=0.8432, x_{5}(0)=0.3531, x_{6}(0)=0.8110$, $x_{7}(0)=0.5319, x_{8}(0)=0.4294$. From Figure 3.1, we can see that $e_{4}$ balance charge between $b_{1}$ and $b_{2}, e_{5}$ balance charge between $b_{3}$ and $b_{4}, e_{6}$ balance charge between $b_{5}$ and $b_{6}, e_{7}$ balance charge between $b_{7}$ and $b_{8}, e_{2}$ balance charge between the sum of $b_{1} b_{2}$ and $b_{3} b_{4}, e_{3}$ balance charge between the sum of $b_{5} b_{6}$ and $b_{7} b_{8}, e_{1}$ balance charge between the sum of $b_{1} b_{2} b_{3} b_{4}$ and $b_{5} b_{6} b_{7} b_{8}$. The evolution of cell SOCs obtained by both simulation and equation (3.10) is shown in Figure 3.2. During the equalization process, all equalizers work simultaneously and independently from each other. The simulation results and the calculated SOCs overlap with each other perfectly. On the other hand, it takes the simulation programs 23.12 seconds on a MacBook Pro with Core i5 CPU and 8GB RAM to generate the complete evolution, while the calculation method only takes 0.90 seconds.

Among all equalizers, the charge that needs to be transferred through $e_{7}$ is the smallest one,$e_{3}$ has the second smallest amount of charge to transfer and $e_{5}$ has the largest amount of charge to transfer. From Fig. 3.2, $t_{1}$ is the equalization time for $e_{7}$, when the balance of SOCs between $b_{7}$ and $b_{8}$ is reached. $t_{2}$ is the equalization time for $e_{3}$, when the balance of SOCs between the sum of $b_{5} b_{6}$ and $b_{7} b_{8}$ is reached. Because charge imbalance between $b_{5}$ and $b_{6}$ still exists at time $t_{2}$, equalizer $e_{6}$ will continue operating until its equalization time $t_{3}$, at which the SOCs of $b_{5} b_{6} b_{7} b_{8}$ are still equalized. Since the difference initial SOCs between two sides of $e_{5}$ is the largest one, the whole system achieve equalization at $t_{3}$. So $t_{3}$ is the equalization time for the entire 
system.

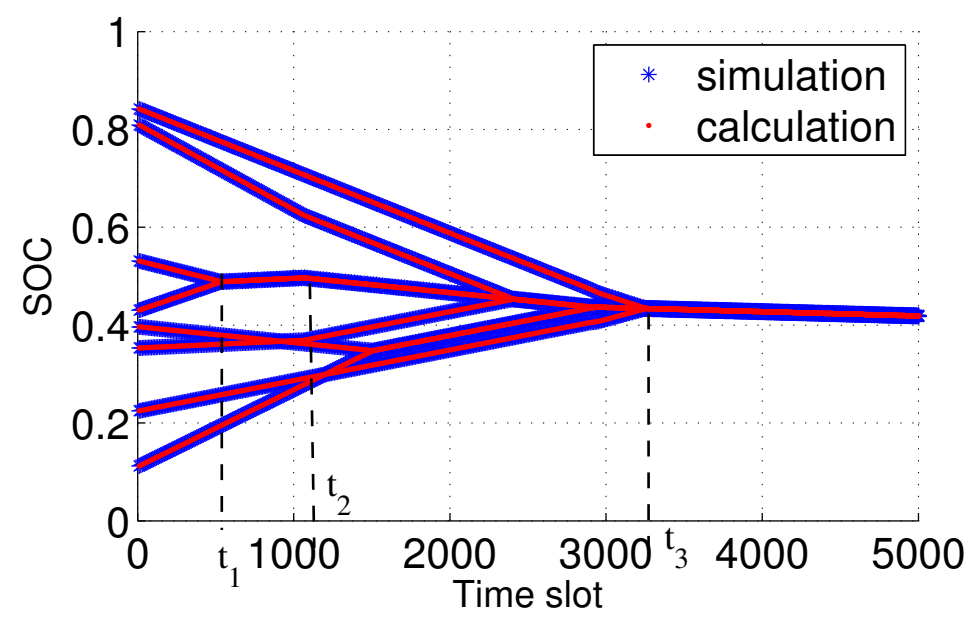

Fig. 3.2: Simulation and calculation of the equalization process of an 8-cell layer-based battery equalization system

\subsection{System performance evaluation with external charging/discharging}

In previous sections, we discuss the situation that $r_{\text {charging }}=0\left(r_{\text {charging }}\right.$ is charging rate). $r_{\text {charging }}=0$ means the system doesn't have external charging or discharging; $r_{\text {charging }}<0$ means the system is discharging; $r_{\text {charging }}>0$ means the system is charging. In this section, we discuss the system performance when equalization and charging/discharging occur simultaneously. When charging the system, external charge goes equally to each cell in the system, which is $r_{\text {charging }} / B$; when discharging the system, charge goes to external load evenly from each cell in the system, which is $r_{\text {charging }} / B$. Since the charge goes equally in or out each cell, for approximation of cell SOCs during equalization, the same method can be directly used, only considering 
charging/discharging part additionally. Specifically, based on equation (3.10), approximation of cell SOCs for layer structure is:

$$
\widehat{x}_{i, \text { charing }}\left(t_{n}\right)=\widehat{x}_{i}\left(t_{n}\right)+\frac{r_{\text {charging }}}{B} t_{n}
$$

Fig. 3.3 shows the simulation results and calculation results obtained by equation (3.13), initial SOCs of the batteries are the same as initial SOCs in Fig. 3.2. Fig.3.3(a) shows system with charing rate $r_{\text {charging }}=5 \cdot 10^{-4}$, Fig.3.3(b) shows system with discharging rate $r_{\text {charging }}=-5 \cdot 10^{-4}$.

It should be noted that some $\widehat{x}_{j}\left(t_{n}\right)$ calculated above may have exceeded upper bound 1 or lower bound 0 before the system finish equalization process. This implies that the system process is terminated because the upper limit or the lower limit of SOC is reached before all cells are equalized. In this case, it is necessary to keep track of the maximum and minimum cell SOCs during the battery equalization process. The upper and lower bound can be calculated as :

$$
\begin{gathered}
\max _{j \in\{1, \ldots, B\}} \widehat{x}_{j}(t)=\max _{\substack{g \in\{1, \ldots, B\} \\
i \in\{1, \ldots, B-g+1\} \\
\bar{x}_{(g, i)}(0) \geq \bar{x}_{(B, 1)}(0)}} \bar{x}_{(g, i)}^{l}(t)+\frac{r_{\text {charging }}}{\tau} t, t \geq 0, \\
\min _{j \in\{1, \ldots, B\}} \widehat{x}_{j}(t)=\min _{\substack{g \in\{1, \ldots, B\} \\
i \in\{1, \ldots, B-g+1\} \\
\bar{x}_{(g, i)}(0) \leq \bar{x}_{(B, 1)}(0)}} \bar{x}_{(g, i)}^{u}(t)+\frac{r_{\text {charging }}}{\tau} t, t \geq 0,
\end{gathered}
$$

where $\bar{x}_{(g, i)}^{l}$ and $\bar{x}_{(g, i)}^{u}$ are lower and upper bound of the average cell SOC of 
$B G(g, i)$ at time $t$ respectively, and are defined as:

$$
\begin{gathered}
\bar{x}_{(g, i)}^{l}(t)=\bar{x}_{(g, i)}(0)+\frac{-\rho_{(g, i)}-(g-1) l_{e}}{g \tau} r_{e} t \\
\bar{x}_{(g, i)}^{u}(t)=\bar{x}_{(g, i)}(0)+\frac{\rho_{(g, i)}\left(1-l_{e}\right)-(g-1) l_{e}}{g \tau} r_{e} t
\end{gathered}
$$

where $g \in\{1, \ldots, B\}, i \in\{1, \ldots, B-g+1\}$. 


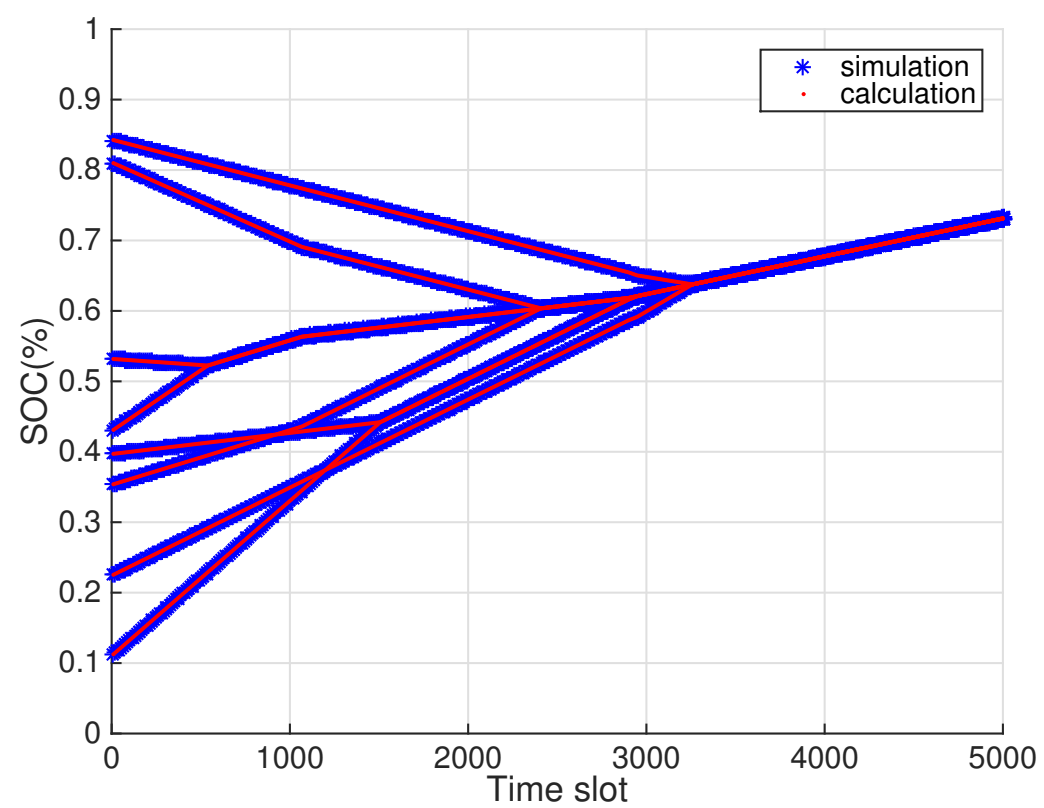

(a) Layer-based system with charging

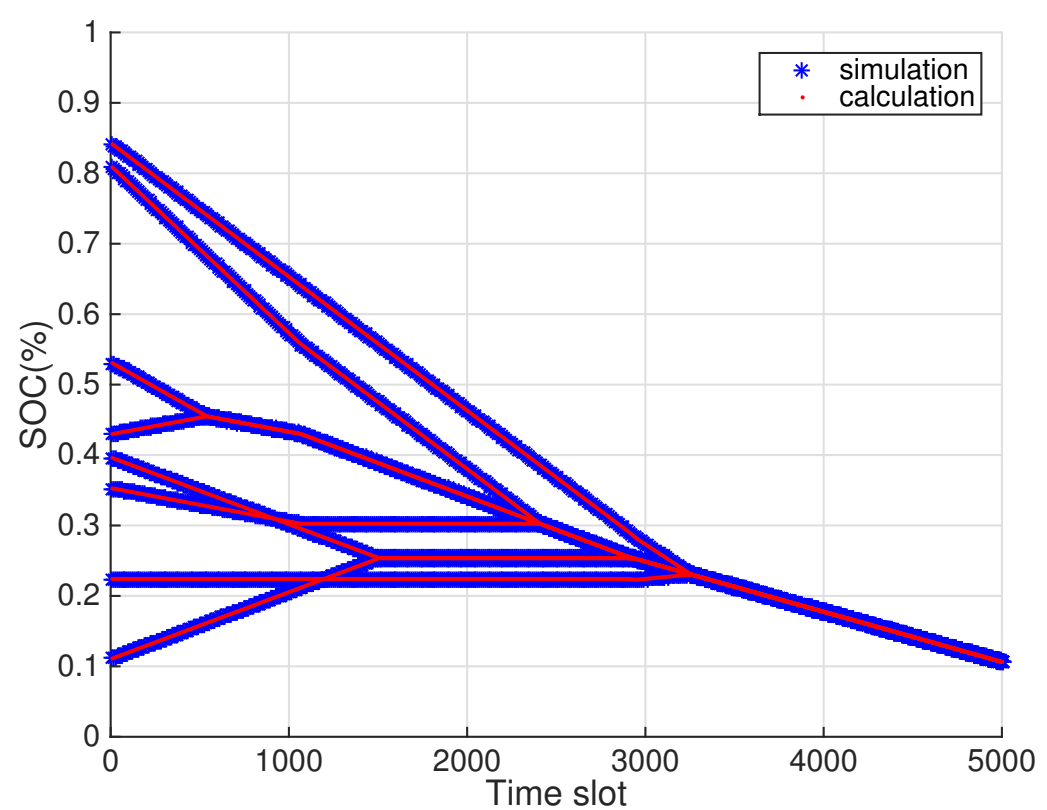

(b) Layer-based system with discharging

Fig. 3.3: Simulation and calculation of the equalization process of a 8-cell battery system in layer-based system with charging/discharging 


\section{Chapter 4}

\section{Module-Based Equalization Structure}

\subsection{Mathematical model}

Based on the assumptions we presented in Chapter 2, a 9-cell module-based battery equalization system is shown in Figure 4.1. This system is evenly divided into 3 modules and each module has 3 cells. In the system, there are two types of equalizers: cell-level equalizers and module-level equalizers. For instance, equalizer $e_{1}$ is celllevel equalizer, it balance the charge between $b_{1}$ and $b_{2}$; equalizer $e_{3}$ is module-level equalizer, it manages substring $b_{1}-b_{2}-b_{3}$ and $b_{4}-b_{5}-b_{6}$. On the other hand, each cell is affected by both cell-level equalizers and module-level equalizers. For instance, cell $b_{1}$ is affected by cell-level equalizer $e_{1}$ and module-level equalizer $e_{3}$, while cell $e_{5}$ is affected by cell-level equalizers $e_{4}, e_{5}$ and module-level equalizers $e_{3}, e_{6}$. Moreover, each module-level equalizer treats each cell in a substring evenly.

In a $B$-cell module-based battery equalization system, each cell is affected by both cell-level equalizers and module-level equalizers, i.e. $e_{1}, e_{2}, \ldots, e_{N-1}, e_{N+1} \ldots$ are cell-level equalizers, $e_{N}, e_{2 N} \ldots e_{B-N}$ are module-level equalizers. Let $S_{C}$ and $S_{M}$ 


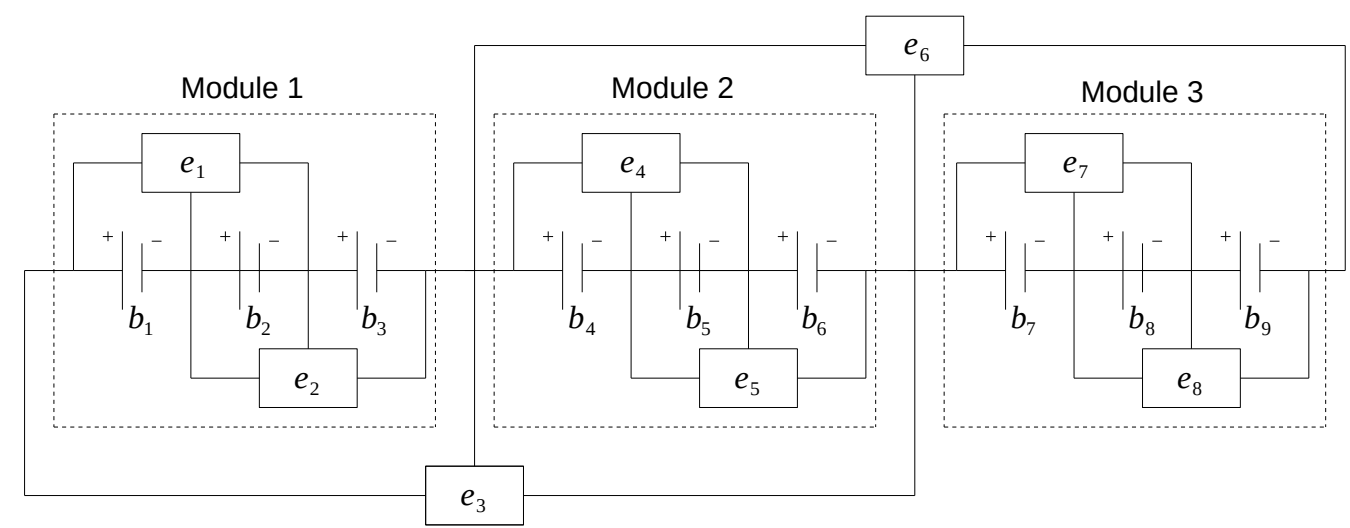

Fig. 4.1: Module-based battery equalization system with $B=9$

represent the index of cell-level equalizers and module-level equalizers respectively. According to the model assumptions, we have:

$$
\begin{array}{r}
S_{C}=\{j N+k \mid j=0, \ldots, M-1 ; k=1, \ldots, N-1\}, \\
S_{M}=\{N, 2 N \ldots,(M-1) N\},
\end{array}
$$

For the equalizer $e_{i}$, let $S_{j}^{+}$and $S_{j}^{-}$represent the sets of battery cells that are on the left-hand side and right-hand side of this equalizer, respectively. For cell-level equalizer, the index of left-hand side battery of $e_{j}$ is $j$, while the index of right-hand side battery of $e_{j}$ is $j+1$. For module-level equalizer, the index of left-hand side battery of $e_{j}$ is $j-N+1, j-N+2, \ldots j$, while the index of right-hand side battery of $e_{j}$ is $j+1, j+2, \ldots, j+N$. That is:

$$
S_{j}^{+}= \begin{cases}\{j-N+1, j-N+2, \ldots, j\}, & \text { if } j \in S_{M}, \\ \{j\}, & \text { if } j \in S_{C},\end{cases}
$$




$$
S_{j}^{-}= \begin{cases}\{j+1, j+2, \ldots, j+N\}, & \text { if } j \in S_{M}, \\ \{j+1\}, & \text { if } j \in S_{C},\end{cases}
$$

Let $\Delta_{j\left(t_{n}\right)}$ denote the total SOC difference between these two battery groups. Then,

$$
\Delta_{j\left(t_{n}\right)}=\sum_{m \in S_{j}^{-}} x_{m}\left(t_{n}\right)-\sum_{m \in S_{j}^{+}} x_{m}\left(t_{n}\right),
$$

Here, we use $\operatorname{sgn}\left(\Delta_{j}\left(t_{n}\right), l_{e}\right)$ defined in equation (3.2) represents the proportion of charges transferred to/from each cell(for cell-level equalizers) or substring(for module-level equalizers). We use indicator function defined in equation (3.3) to determine whether battery $i$ belongs to the substring. Clearly, if $I_{S_{j}^{+}}=I_{S_{j}^{-}}=0$, the equalizer have no influence to battery $i$; if $I_{S_{j}^{+}}=1, I_{S_{j}^{-}}=0$, the battery $i$ is on the left-hand side of the equalizer; if $I_{S_{j}^{+}}=0, I_{S_{j}^{-}}=1$, the battery $i$ is on the right-hand side of the equalizer. The charge transfer scenarios for each of these three cases are described below:

i When $i \notin S_{j}^{+}$and $i \notin S_{j}^{-}$, in this case, the $j$-th equalizer does not contribute to $b_{i}$ and no charge transfer occurs in $b_{i}$ due to this equalizer.

ii When $i \in S_{j}^{+}$, there are two possibilities in this cases:

(a) When $j \in S_{M}$, which means equalizer $j$ is a module-level equalizer. In this case, cell $b_{i}$ is in the substring of the left-hand side of module-level equalizer $e_{j}$. There are three situation in this case: 
1 When $\Delta_{j}\left(t_{n}\right)>0$, the total charge of the substring on the right-hand side of $j$-th module-level equalizer is larger than that on the left-hand side. Under this situation, the cells within $S_{j}^{+}$receive a total of $\left(1-l_{e}\right) r_{m}$ units of charge during this time slot, which is evenly distributed to each one, i.e., $\frac{\left(1-l_{e}\right) r_{m}}{N}$ per cell. On the other hand, the cells within $S_{j}^{-}$lose a total of $r_{m}$ units of charge during this time slot, which is also evenly distributed to each one, i.e., $\frac{r_{m}}{N}$ for each cell.

2 When $\Delta_{j}\left(t_{n}\right)<0$, the total charge of the substring on the left-hand side of $j$-th module-level equalizer is larger than that on the right-hand side. Under this situation, the cells within $S_{j}^{-}$receive a total of $\left(1-l_{e}\right) r_{m}$ units of charge during this time slot, which is evenly distributed to each one, i.e., $\frac{\left(1-l_{e}\right) r_{m}}{N}$ per cell. On the other hand, the cells within $S_{j}^{+}$lose a total of $r_{m}$ units of charge during this time slot, which is also evenly distributed to each one, i.e., $\frac{r_{m}}{N}$ for each cell.

3 When $\Delta_{j}\left(t_{n}\right)=0$, the total charge of the substring on the left-hand side of $j$-th equalizer is as same as that on the right-hand side. Under this situation, no charge transferred.

(b) When $j \in S_{C}$, which means equalizer $j$ is a cell-level equalizer. In this case, cell $b_{i}$ is in the left-hand side of cell-level equalizer $e_{j}$. There are three situation in this case:

1 When $\Delta_{j}\left(t_{n}\right)>0$, the charge of the cell on the right-hand side of $j$-th 
cell-level equalizer is larger than that on the left-hand side. Under this situation, cell $b_{j}$ receives $\left(1-l_{e}\right) r_{c}$ units of charge during this time slot. On the other hand, cell $b_{j+1}$ loses $r_{c}$ units of charge during this time slot.

2 When $\Delta_{j}\left(t_{n}\right)<0$, the charge of the cell on the left-hand side of $j$-th cell-level equalizer is larger than that on the right-hand side. Under this situation, cell $b_{j+1}$ receives $\left(1-l_{e}\right) r_{c}$ units of charge during this time slot. On the other hand, cell $b_{j}$ loses $r_{c}$ units of charge during this time slot.

3 When $\Delta_{j}\left(t_{n}\right)=0$, the charge on the left-hand side of $j$-th equalizer is as same as that on the right-hand side. Under this situation, no charge is transferred.

iii When $i \in S_{j}^{-}$, the two cases are similar to part (b).

Again, let $t_{n}=n \tau, n=0,1,2, \ldots$, and let $x_{i}(t) \in[0,1], i=1, \ldots, B$, denote the SOC of cell $b_{i}$ at time $t \geq 0$. Then, the evolution of the system is given by

$$
x_{i}(t)=x_{i}\left(t_{n}\right)+k_{i}\left(t_{n}\right)\left(t-t_{n}\right), t \in\left(t_{n}, t_{n+1}\right], n=0,1, \ldots,
$$

where $k_{i}\left(t_{n}\right)$ is the overall charge transfer rate of cell $b_{i}$ during time $\left(t_{n}, t_{n+1}\right]$ :

$k_{i}\left(t_{n}\right)=\sum_{j=1}^{B-1}\left(\operatorname{sgn}\left(\Delta_{j}\left(t_{n}\right), l_{e}\right) \cdot\left[I_{S_{j}^{+}}(i)-I_{S_{j}^{-}}(i)\right] \cdot \frac{r_{c} I_{S_{C}}(j)+r_{m} I_{S_{M}}(j)}{1+(N-1) I_{S_{M}}(j)}\right), \quad i=1, \ldots, B$,

and $\operatorname{sgn}(\cdot, \cdot)$ and $I_{A}(\cdot)$ are defined in (3.2) and (3.3), respectively.

To study such systems, an analytical algorithm is proposed in [42] for modulebased battery equalization systems with no charge loss, i.e., when $l_{c}=l_{m}=0$. The 
algorithm notes that the cell-level equalization and module-level equalization are independent and treats each module individually by viewing a module as an independent series-connected subsystem. Then, the equalization time for each of these subsystems can be calculated. Next, each module is viewed as an "aggregated cell" such that the entire system again can be analyzed as a series-connected one. Finally, the maximum of the equalization times of the subsystems and the aggregated system is used to approximate the equalization time of the overall system. In this paper, the idea is extended to the cases where $l_{c}$ and $l_{m}$ are greater than zero by applying the methods derived in [12] for series-based battery equalization systems with charge loss.

\subsection{Equalization time}

\subsubsection{Calculation algorithm}

\section{Algorithm 1:}

Step 1: For each module $i$ in the system, $i=1, \ldots, M$, calculate its intra-module equalization time, $\widehat{T}_{e, i}^{i n t r a}$, as

$$
\widehat{T}_{e, i}^{i, t r a}=\max _{g \in\{1, \ldots, N-1\}} t_{e, i}^{i n t r a}(g, p),
$$


where $p=(i-1) N+1$ is the index of the first battery in Module $i$,

$$
t_{e, i}^{i n t r a}(g, p)=\left\{\begin{array}{c}
\frac{\bar{x}_{(g, p)}(0)-\bar{x}_{(N, p)}(0)}{-\left(\left(\frac{1}{g}-\frac{1}{N}\right) l_{c}-\frac{1}{g}\right) r_{c}}, \\
\text { if } \bar{x}_{(g, p)}(0)>\bar{x}_{(N, p)}(0), \\
\frac{\bar{x}_{(g, p)}(0)-\bar{x}_{(N, p)}(0)}{-\left(\left(\frac{1}{g}-\frac{1}{N}\right) l_{c}+\frac{\left(1-l_{c}\right)}{g}\right) r_{c}}, \\
\text { if } \bar{x}_{(g, p)}(0)<\bar{x}_{(N, p)}(0),
\end{array}\right.
$$

and $\bar{x}_{(g, p)}(0)$ is the average initial SOC of battery string $b_{p}-b_{p+1^{-}} \ldots-b_{p+g-1}$ :

$$
\bar{x}_{(g, p)}(0)=\frac{1}{g} \sum_{i=p}^{p+g-1} x_{i}(0), \quad g=1, \ldots, N .
$$

Step 2: View each module $i$ as an aggregated battery cell with its aggregated SOC defined as

$$
X_{i}(t)=\sum_{j=p}^{p+N-1} x_{j}(t)
$$

Step 3: Consider the series-connected equalization system with the aggregated batteries constructed in Step 2. Calculate the inter-module equalization time, $\widehat{T}_{e}^{i n t e r}$, based on

$$
\widehat{T}_{e}^{i n t e r}=\max _{g \in\{1, \ldots, M-1\}} t_{e}^{\text {inter }}(g, 1)
$$

where

$$
t_{e}^{\text {inter }}(g, 1)=\left\{\begin{array}{c}
\frac{\bar{X}_{(g, 1)}(0)-\bar{X}_{(M, 1)}(0)}{-\left(\left(\frac{1}{g}-\frac{1}{M}\right) l_{m}-\frac{1}{g}\right) r_{m}}, \\
\text { if } \bar{X}_{(g, 1)}(0)>\bar{X}_{(M, 1)}(0), \\
\frac{\bar{X}_{(g, 1)}(0)-\bar{X}_{(M, 1)}(0)}{-\left(\left(\frac{1}{g}-\frac{1}{M}\right) l_{m}+\frac{\left(1-l_{m}\right)}{g}\right) r_{m}}, \\
\text { if } \bar{X}_{(g, 1)}(0)<\bar{X}_{(M, 1)}(0),
\end{array}\right.
$$




$$
\begin{gathered}
\bar{X}_{(g, 1)}(0)=\frac{1}{g} \sum_{i=1}^{g} X_{i}(0), \quad g=1, \ldots, M \\
t_{e, i}^{\text {intra }}(g, p)=\left\{\begin{array}{c}
\frac{\bar{x}_{(g, p)}(0)-\bar{x}_{(N, p)}(0)}{-\left(\left(\frac{1}{g}-\frac{1}{N}\right) l_{c}-\frac{1}{g}\right) r_{c}}, \\
\text { if } \bar{x}_{(g, p)}(0)>\bar{x}_{(N, p)}(0), \\
\frac{\bar{x}_{(g, p)}(0)-\bar{x}_{(N, p)}(0)}{-\left(\left(\frac{1}{g}-\frac{1}{N}\right) l_{c}+\frac{\left(1-l_{c}\right)}{g}\right) r_{c}}, \\
\text { if } \bar{x}_{(g, p)}(0)<\bar{x}_{(N, p)}(0),
\end{array}\right.
\end{gathered}
$$

Step 4: The equalization time of the overall system can be approximated by

$$
\widehat{T}_{e}^{\text {module }}=\max \left\{\widehat{T}_{e}^{i n t e r}, \max _{i=1, \ldots, M} \widehat{T}_{e, i}^{i n t r a}\right\}
$$

\subsubsection{Validation by simulation}

In order to justify the accuracy of Algorithm 1, a MATLAB program is created to "simulate" the system behavior based on the mathematical model defined above, i.e., by iteratively calculating the values of $x_{i}\left(t_{n}\right)$ based on equation (4.6). To carry out the numerical experiments, we run the program on systems with the number of cells ranging from $B \in\{4,8,16,32\}$. For each $B$, we select $M \in\{2,4, \ldots, B / 2\}$, the equalization rate from $r_{c}, r_{m} \in\left\{10^{-4}, 10^{-5}\right\}$ and use $l_{c}=l_{m}=0.1$. For each combination of $B, M, r_{c}$ and $r_{m}, 5000$ samples are tested with initial SOCs randomly and independently generated from uniform distribution $U(0,1)$. For each sample, we evaluate its true equalization time $T_{e}^{\text {module }}$ from simulation and compare it with $\widehat{T}_{e}^{\text {module }}$ calculated 
based on Algorithm 1. The accuracy is evaluated using the percentage error between the two values:

$$
\epsilon_{e}=\frac{\left|T_{e}^{\text {module }}-\widehat{T}_{e}^{\text {module }}\right|}{T_{e}^{\text {module }}} \cdot 100 \%
$$

The results are summarized in Table 4.1. As we can see, the average error $\bar{\epsilon}_{e}$ is very small for all cases, which implies that the calculated equalization time is close to the true value. Thus, we claim that Algorithm 1 can be used to calculate the equalization time for module-based equalization system.

Table 4.1: Average approximation error of equalization time under module-based structure

\begin{tabular}{|c|c|c|c|}
\hline \multicolumn{2}{|c|}{$r_{c}=r_{m}=10^{-4}$} & \multicolumn{2}{|c|}{$r_{c}=r_{m}=10^{-5}$} \\
\hline$B: 4, M: 2$ & $B: 8, M: 2$ & $B: 4, M: 2$ & $B: 8, M: 2$ \\
$0.0579 \%$ & $0.7306 \%$ & $0.0057 \%$ & $0.0730 \%$ \\
\hline$B: 8, M: 4$ & $B: 16, M: 2$ & $B: 8, M: 4$ & $B: 16, M: 2$ \\
$0.9236 \%$ & $1.4502 \%$ & $0.0924 \%$ & $0.1450 \%$ \\
\hline$B: 16, M: 4$ & $B: 16, M: 8$ & $B: 16, M: 4$ & $B: 16, M: 8$ \\
$0.0675 \%$ & $0.1298 \%$ & $0.0068 \%$ & $0.0130 \%$ \\
\hline$B: 32, M: 2$ & $B: 32, M: 4$ & $B: 32, M: 2$ & $B: 32, M: 4$ \\
$2.0840 \%$ & $1.7102 \%$ & $0.2084 \%$ & $0.1710 \%$ \\
\hline$B: 32, M: 8$ & $B: 32, M: 16$ & $B: 32, M: 8$ & $B: 32, M: 16$ \\
$1.8034 \%$ & $1.9887 \%$ & $0.1803 \%$ & $0.1989 \%$ \\
\hline
\end{tabular}




\subsection{Approximation of cell SOCs during equalization}

\subsubsection{Calculation formula}

Similar to Section 2, iterative calculation of $x_{i}\left(t_{n}\right)$ based on equation (4.6) is very time consuming when $r_{c}$ or $r_{m}$ is small. To alleviate this problem, note that the module-based system considered here can be viewed as a group of series-based battery equalization systems that have been studied in [12]. Therefore, the following algorithm is proposed:

\section{Algorithm 2:}

Step 1: Consider Module $i$ as a virtual series-based battery equalization system consisting of the $N$ cells in the module and the cell-level equalizers. Apply Algorithm 1 developed in [12] to calculate the approximated SOC of the $j$-th battery in this virtual system, denoted as $\widehat{x}_{j}^{(i)}(t), i=1, \ldots, M, j=1, \ldots, N$.

Step 2: View each module $i$ as an aggregated battery cell with its aggregated SOC defined in (4.11). Consider another virtual $M$-cell series-based battery equalization system consisting of these aggregated battery cells and the module-level equalizers.

Step 3: Apply Algorithm 1 developed in [12] to calculate the approximated SOC of the $j$-th battery cell of the virtual system constructed in Step 2, denoted as $\widehat{X}_{j}(t), j=1, \ldots, M$.

Step 4: The SOC of the $j$-th battery cell in the original module-based equalization 
system can be approximated as:

$$
\widehat{x}_{j}(t)=\widehat{x}_{j-\left\lfloor\frac{j-1}{N}\right\rfloor N}^{\left(\left\lfloor\frac{j-1}{N}\right\rfloor+1\right)}(t)+\frac{\widehat{X}_{\left\lfloor\frac{j-1}{N}\right\rfloor+1}(t)-X_{\left\lfloor\frac{j-1}{N}\right\rfloor+1}(0)}{N} .
$$

\subsubsection{Validation by simulation}

In order to test the accuracy of Algorithm 2, the same simulation program and the same data set generated above are used. For each sample, we first simulate the system by iteratively calculating the values for all $x_{i}\left(t_{n}\right)$ 's until all cells are equalized. Then, the approximated SOCs $\widehat{x}_{i}\left(t_{n}\right)$ are calculated based on Algorithm 2. The accuracy of the method is evaluated based on:

$$
\epsilon_{S O C}=\frac{\sum_{i=1}^{B} \sum_{n=0}^{\left\lfloor T_{e} / \tau\right\rfloor} \frac{\left|\widehat{x}_{i}\left(t_{n}\right)-x_{i}\left(t_{n}\right)\right|}{x_{i}\left(t_{n}\right)}}{B\left(\left\lfloor T_{e} / \tau\right\rfloor+1\right)} \cdot 100 \%
$$

The results are summarized in the Table 4.2. As we can see, the average error $\bar{\epsilon}_{S O C}(B)$ is again very small. Therefore, we claim that Algorithm 2 can be used to approximate the cell SOCs for the battery system during the equalization process.

As we can see in table $4.2, \bar{\epsilon}_{S O C}(B)$ is very small, which means the approximation of calculated cell SOCs during equalization process are close to simulation results. What's more, as equalization rate for equalizer reduce by 10 times, $\bar{\epsilon}_{S O C}(B)$ also reduce by 10 times. Therefore, we claim that algorithm 3.2 can be used to calculate equalization time for layer-based battery equalization system.

As an illustration, consider a module-based battery equalization system with parameters $B=9, M=3, r_{c}=r_{m}=10^{-5}$, and $l_{c}=l_{m}=0.1$. The initial SOCs 
Table 4.2: Average approximation error of cell SOCs under module-based structure

\begin{tabular}{|c|c|c|c|}
\hline \multicolumn{2}{|c|}{$r_{c}=r_{m}=10^{-4}$} & \multicolumn{2}{|c|}{$r_{c}=r_{m}=10^{-5}$} \\
\hline$B: 4, M: 2$ & $B: 8, M: 2$ & $B: 4, M: 2$ & $B: 8, M: 2$ \\
$0.0657 \%$ & $0.2706 \%$ & $0.0066 \%$ & $0.0271 \%$ \\
\hline$B: 8, M: 4$ & $B: 16, M: 2$ & $B: 8, M: 4$ & $B: 16, M: 2$ \\
$0.0657 \%$ & $0.2203 \%$ & $0.0208 \%$ & $0.0219 \%$ \\
\hline$B: 16, M: 4$ & $B: 16, M: 8$ & $B: 16, M: 4$ & $B: 16, M: 8$ \\
$0.1537 \%$ & $0.1632 \%$ & $0.0154 \%$ & $0.0163 \%$ \\
\hline$B: 32, M: 2$ & $B: 32, M: 4$ & $B: 32, M: 2$ & $B: 32, M: 4$ \\
$0.5235 \%$ & $0.2987 \%$ & $0.0524 \%$ & $0.0300 \%$ \\
\hline$B: 32, M: 8$ & $B: 32, M: 16$ & $B: 32, M: 8$ & $B: 32, M: 16$ \\
$0.2019 \%$ & $0.2540 \%$ & $0.0202 \%$ & $0.0255 \%$ \\
\hline
\end{tabular}


of the cells are $x_{1}(0)=0.5975, x_{2}(0)=0.2238, x_{3}(0)=0.1079, x_{4}(0)=0.4035$, $x_{5}(0)=0.4504, x_{6}(0)=0.3600, x_{7}(0)=0.1749, x_{8}(0)=0.7269, x_{9}(0)=0.9081$. From Figure 4.1, we can see that $e_{4}$ balances charge between $b_{1}$ and $b_{2}, e_{5}$ balances charge between $b_{3}$ and $b_{4}, e_{6}$ balances charge between $b_{5}$ and $b_{6}, e_{7}$ balances charge between $b_{7}$ and $b_{8}, e_{2}$ balances charge between the sum of $b_{1} b_{2}$ and $b_{3} b_{4}, e_{3}$ balances charge between the sum of $b_{5} b_{6}$ and $b_{7} b_{8}, e_{1}$ balances charge between the sum of $b_{1} b_{2} b_{3} b_{4}$ and $b_{5} b_{6} b_{7} b_{8}$. The evolution of cell SOCs obtained by both simulation and Algorithm 2 is shown in Figure 4.2. Take $b_{1}$ for example: its associated module, Module 1 , is equalized with Module 2 through module-level equalizer $e_{3}$ balances charge between the sum of $b_{1} b_{2} b_{3}$ finish balancing first at time $t_{1}$, so the equalization rate for $b_{1}$ change at time $t_{1}$. Then, $b_{1}$ merge $b_{2}$ and $b_{3}$ at time $t_{2}$. By time $t_{2}$ batteries $b_{1}$ to $b_{6}$ all merge together. Finally, at time $t_{3}$, module-level equalizer $e_{6}$ finish balancing, equalization process finish and $t_{3}$ is the equalization time for whole system. As one can see, the simulation results and the calculated SOCs overlap with each other perfectly.

\subsection{System performance evaluation with external charging/discharging}

In previous sections, we discussed the situation that $r_{\text {charging }}=0\left(r_{\text {charging }}\right.$ is charging rate). $r_{\text {charging }}=0$ means the system doesn't have external charging or discharging; $r_{\text {charging }}<0$ means the system is discharging; $r_{\text {charging }}>0$ means the system is charging. In this section, we discuss the system performance when equalization and charging/discharging occur simultaneously. When charging the system, external charge 


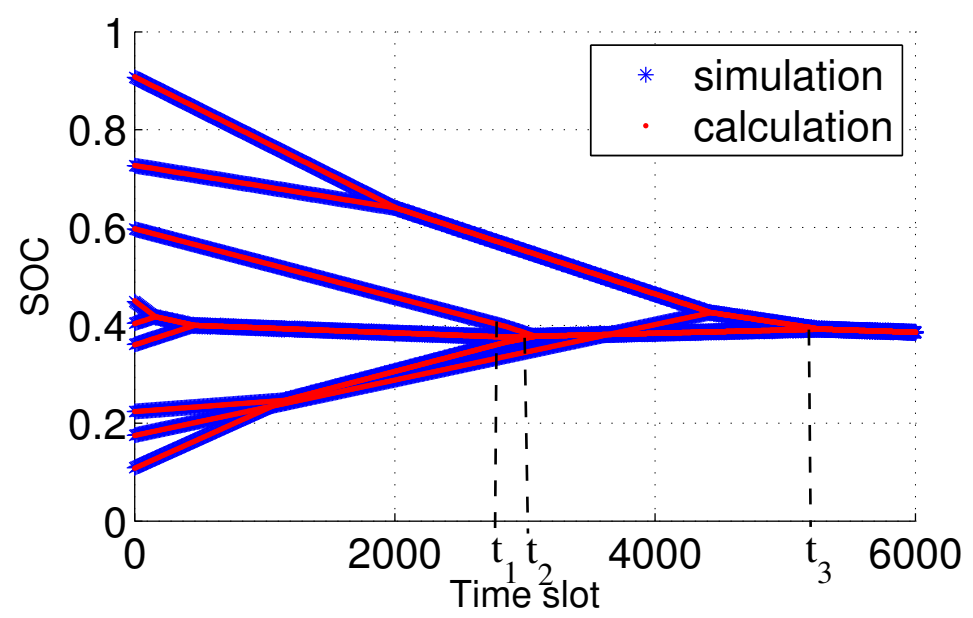

Fig. 4.2: Simulation and calculation of the equalization process of a 9-cell modulebased battery equalization system

goes equally to each cell in the system, which is $r_{\text {charging }} / B$; when discharging the system, charge goes to external load evenly from each cell in the system, which is $r_{\text {charging }} / B$. Since charge goes equally in or out each cell, for approximation of cell SOCs during equalization, the same method can be directly used for both layer and module based system, only considering charging/discharging part additionally. For module structure, based on equation (4.17), approximation of cell SOCs for module structure is:

$$
\widehat{x}_{i, \text { charing }}\left(t_{n}\right)=\widehat{x}_{i}\left(t_{n}\right)+\frac{r_{\text {charging }}}{B} t_{n}
$$

Fig. 4.3 shows the simulation results and calculation results obtained by equation (4.19), initial SOCs of the batteries are the same as initial SOCs in Fig. 4.2. Fig.4.3(a) shows system with charing rate $r_{\text {charging }}=5 \cdot 10^{-4}$, Fig.4.3(b) shows system with 
discharging rate $r_{\text {charging }}=-5 \cdot 10^{-4}$.

Similar to the discussion in the Section 3.4 , system process may terminated because the upper limit or the lower limit of SOC is reached before all cells are equalized. The trajectories of the maximum and minimum cell SOCs during the battery equalization process are similar to the layer-based structure, which is shown in equations (3.14), (3.15), (3.16) and (3.17). 


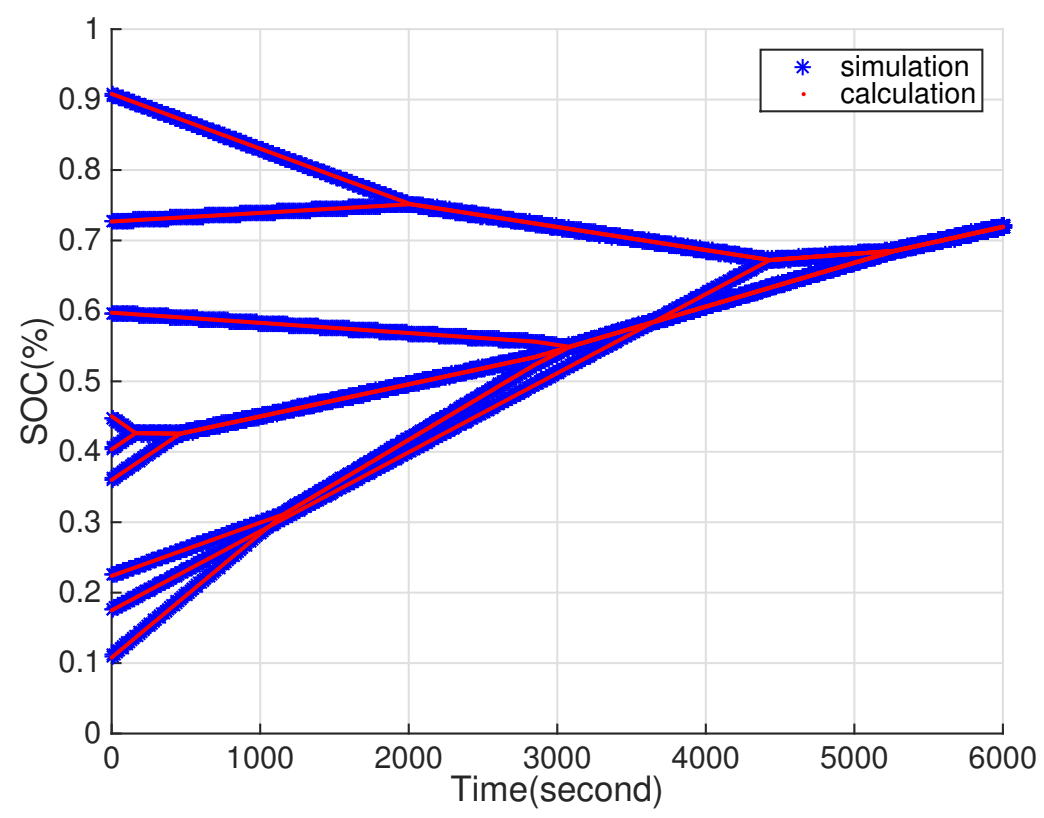

(a) Module-based system with charging

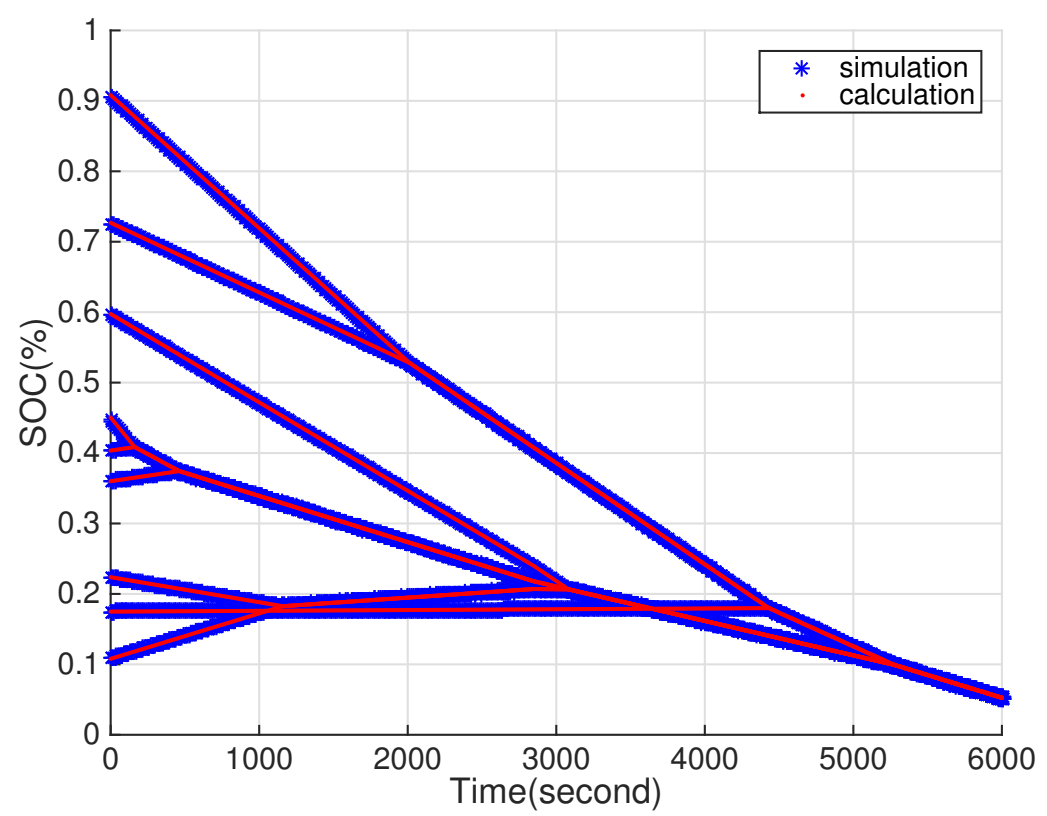

(b) Module-based system with discharging

Fig. 4.3: Simulation and calculation of the equalization process of a 9-cell battery system in module-based system with charging/discharging 


\section{Chapter 5}

\section{Comparisons}

\subsection{Statistical comparison}

For battery equalization system, we want to minimize energy loss to save energy. The energy loss in a battery equalization system is given by:

$$
x_{\text {loss }}=(B-1) T_{e} l_{e} r_{e}
$$

Here, $x_{\text {loss }}$ is the entire energy loss from start to the end of equalization process. Clearly, we can reduce energy loss by decreasing the equalization time.

To compare equalization time for layer-based and module-based structure generally, 10000 samples are tested with initial SOCs randomly generated on uniform distribution $U(0,1)$. We select the number of cell $B=8,16,32$ and 64 . For the modulebased structure, we enumerate all possible $M$ 's from $\{2,4, \ldots, B / 2\}$. In addition, we assume that all equalizers have the same equalization rate $r=10^{-4}$ and energy loss rate $l=0.1$. Average equalization time and percentage of shortest equalization time for different structure are shown in Table 5.1 to Table 5.8.

As one can see from the table, the layer-based structure provides the best average 
Table 5.1: Average equalization time in three structures $(B=8)$

\begin{tabular}{|l|l|l|l|}
\hline Layer & Module & Module & Series \\
& $N=2$ & $N=4$ & \\
\hline 5094 & 5303 & 5242 & 5785 \\
\hline
\end{tabular}

Table 5.2: Percentage of shortest equalization time for three structures $(B=8)$

\begin{tabular}{|l|l|l|l|}
\hline Layer & Module & Module & Series \\
& $N=2$ & $N=4$ & \\
\hline $44.92 \%$ & $22.55 \%$ & $17.73 \%$ & $14.81 \%$ \\
\hline
\end{tabular}

Table 5.3: Average equalization time in three structures $(B=16)$

\begin{tabular}{|l|l|l|l|l|}
\hline Layer & Module & Module & Module & Series \\
& $N=2$ & $N=4$ & $N=8$ & \\
\hline 7241 & 8171 & 7615 & 7904 & 8924 \\
\hline
\end{tabular}

Table 5.4: Percentage of shortest equalization time for three structures $(B=16)$

\begin{tabular}{|l|l|l|l|l|}
\hline Layer & Module & Module & Module & Series \\
& $N=2$ & $N=4$ & $N=8$ & \\
\hline $49.58 \%$ & $14.89 \%$ & $17.25 \%$ & $11.00 \%$ & $7.27 \%$ \\
\hline
\end{tabular}


Table 5.5: Average equalization time in three structures $(B=32)$

\begin{tabular}{|l|l|l|l|l|l|}
\hline Layer & Module & Module & Module & Module & Series \\
& $N=2$ & $N=4$ & $N=8$ & $N=16$ & \\
\hline 10286 & 12520 & 11561 & 11078 & 11744 & 13337 \\
\hline
\end{tabular}

Table 5.6: Percentage of shortest equalization time for three structures $(B=32)$

\begin{tabular}{|l|l|l|l|l|l|}
\hline Layer & Module & Module & Module & Module & Series \\
& $N=2$ & $N=4$ & $N=8$ & $N=16$ & \\
\hline $53.10 \%$ & $8.39 \%$ & $15.03 \%$ & $13.31 \%$ & $6.59 \%$ & $3.59 \%$ \\
\hline
\end{tabular}

Table 5.7: Average equalization time inthree structures $(B=64)$

\begin{tabular}{|l|l|l|l|l|l|l|}
\hline Layer & Module & Module & Module & Module & Module & Series \\
& $N=2$ & $N=4$ & $N=8$ & $N=16$ & $N=32$ & \\
\hline 14478 & 18665 & 17603 & 16417 & 15962 & 17089 & 19473 \\
\hline
\end{tabular}

Table 5.8: Percentage of shortest equalization time for three structures $(B=64)$

\begin{tabular}{|l|l|l|l|l|l|l|}
\hline Layer & Module & Module & Module & Module & Module & Series \\
& $N=2$ & $N=4$ & $N=8$ & $N=16$ & $N=32$ & \\
\hline $58.26 \%$ & $3.67 \%$ & $8.82 \%$ & $13.52 \%$ & $9.99 \%$ & $4.11 \%$ & $1.62 \%$ \\
\hline
\end{tabular}


performance among the all three structures for all B's considered, whereas the seriesbased structure appears to have the worst average performance. Specifically, the layerbased structure can reduce the average equalization time by about $25 \%$ for $B=64$ from series-based structure. The best case module-based structure, on the other hand, can reduce average equalization time by about $18 \%$ for $B=64$. What's more, under most circumstance, layer-based equalization structure perform shortest equalization time. It should be noted that, although the layer- and module-based structures can improve the average equalization performance over the series-based structure, there are cases in which the series-based structure outperforms these two. The frequency of cases where the layer-, module- and series-based result in the shortest equalization time are given in Table 5.2, 5.4, 5.6 and 5.8 for $B=8,16,32,64$ respectively. As we can see, for $B=8$, although the average equalization time of layer- and module-based structures are shorter than those under the series-based structure, there are still a lot of cases that there is no improvement using layer- and module-based structure. However, as the number of batteries increases, the superiority of the layer- and module-based equalization structures becomes more and more prominent. For example, when $B=$ 64 , series-based structure perform best in less than $2 \%$ of cases. Layer-based structure perform best in around $58 \%$ cases, whereas the module-base structure in about $40 \%$ cases. Since the number of battery cells in real applications is usually large, the layerbased or module-based equalization structure should be considered over the traditional series-based structure for better equalization performance. 


\subsection{Illustration}

Example 1: Consider an eight-battery system with initial battery SOCs as: $x_{1}(0)=$ $0.3964, x_{2}(0)=0.6388, x_{3}(0)=0.5947, x_{4}(0)=0.5093, x_{5}(0)=0.4835, x_{6}(0)=$ $0.8368, x_{7}(0)=0.1921, x_{8}(0)=0.1509$. The equalization process using layer-based structure and module-based structure are shown in Fig. 5.1. For layer-based structure, equalization time is 5144 time slots; for module-based structure, equalization time is 6232 time slots. In this example, initial SOCs for $b_{7}$ and $b_{8}$ are relatively small. For module-based structure, only one equalizer transfer charge into this battery group which slow down the equalization process. However, for layer-based structure, equalizers in three layers can simultaneously work to charge $b_{7}$ and $b_{8}$.

Example 2: Consider an eight-battery system with initial battery SOCs as: $x_{1}(0)=$ $0.0009, x_{2}(0)=0.9132, x_{3}(0)=0.5288, x_{4}(0)=0.0317, x_{5}(0)=0.0227, x_{6}(0)=$ $0.0641, x_{7}(0)=0.2329, x_{8}(0)=0.8997$. The equalization process using layer-based structure and module-based structure are shown in Fig. 5.2. For layer-based structure, equalization time is 5504 time slots; for module-based structure, equalization time is 4963 time slots. In this example, the sum SOC of $b_{5} b_{6}$ is relatively small, while the sum SOC of $b_{7} b_{8}$ is relatively large. In layer-based structure, only one equalizer is responsible for transferring charge from $b_{7} b_{8}$ to $b_{5} b_{6}$. However, in module-based structure, two equalizers charge $b_{5} b_{6}$ simultaneously, which reduce the equalization time. 


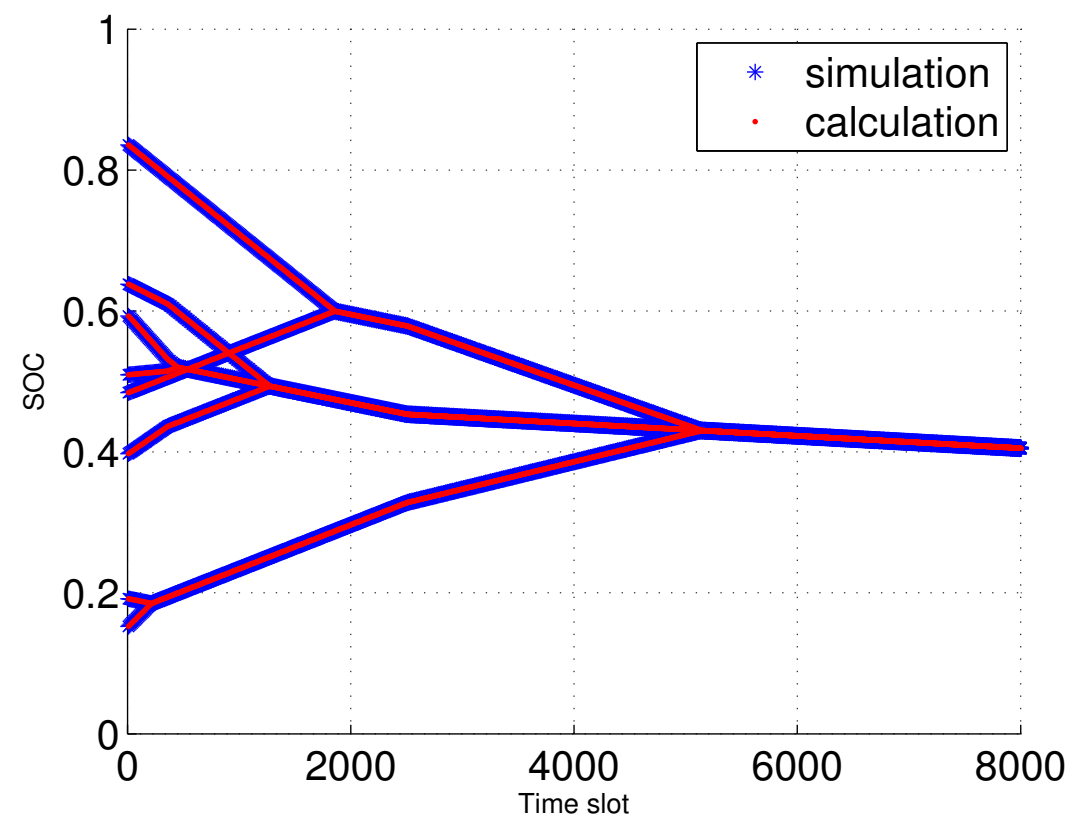

(a) Layer-based system

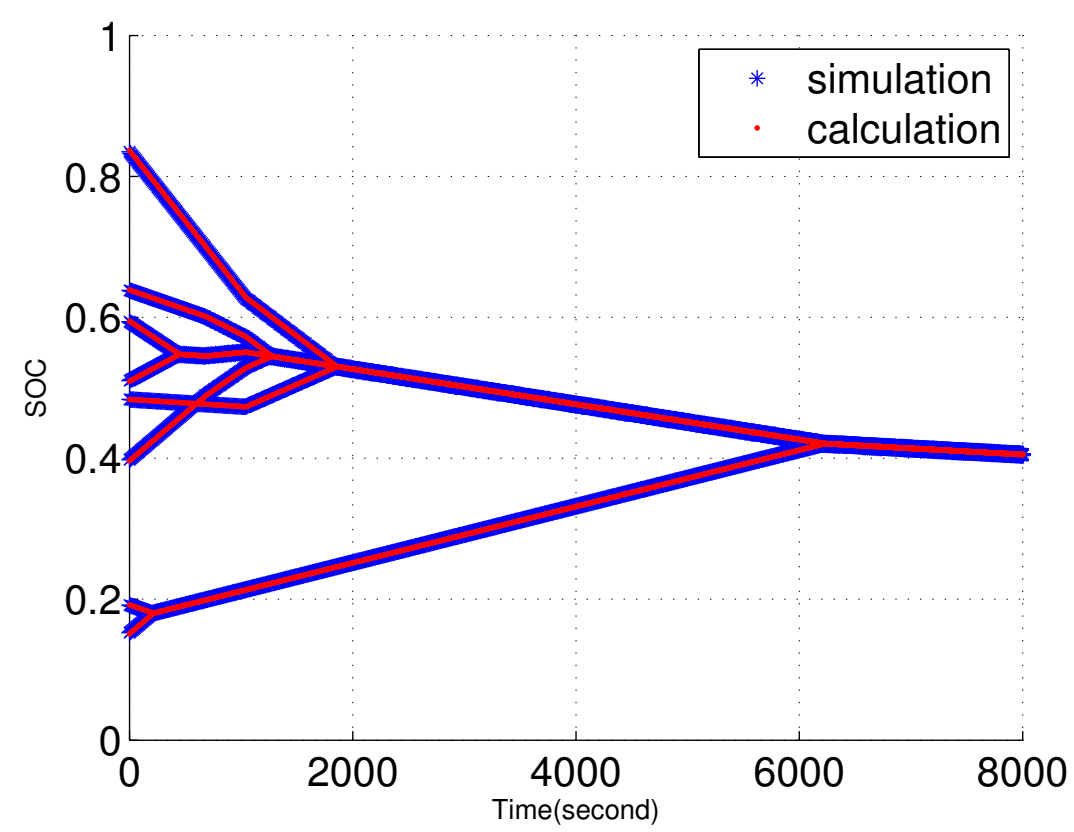

(b) Module-based system

Fig. 5.1: Battery equalization processes under two structures in Example 1. (a) Layerbased equalization. (b) Module-based equalization 


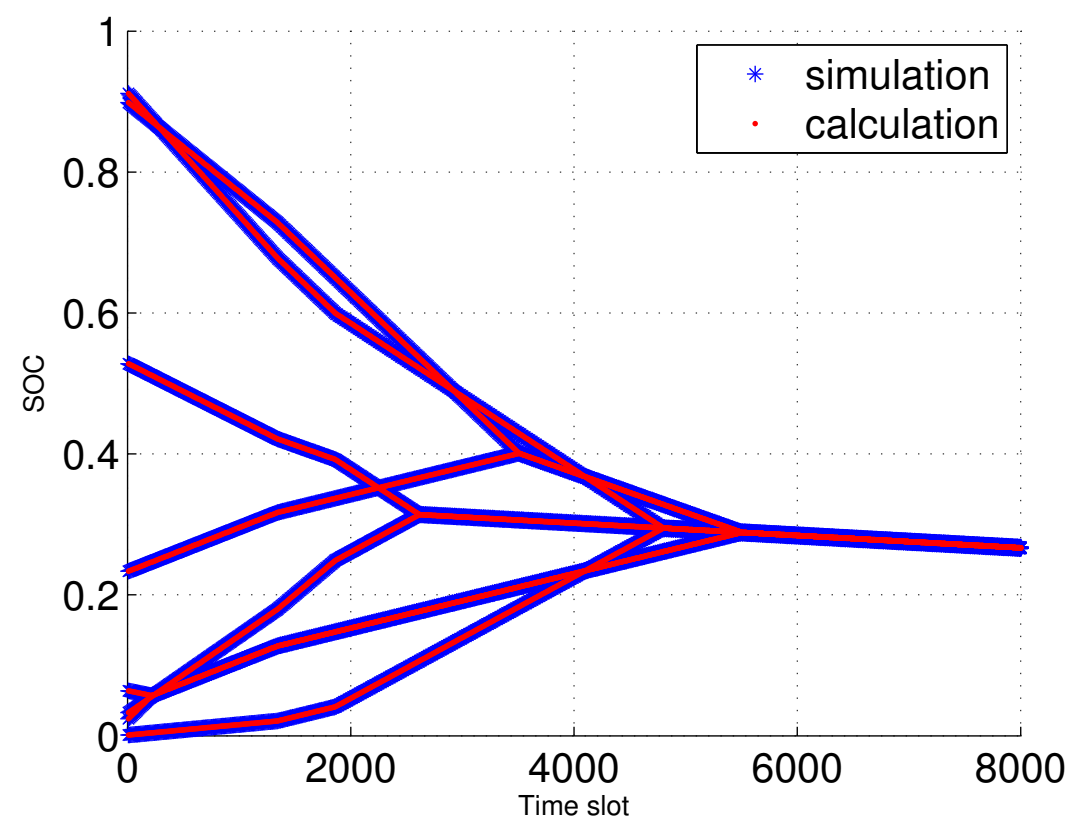

(a) Layer-based system

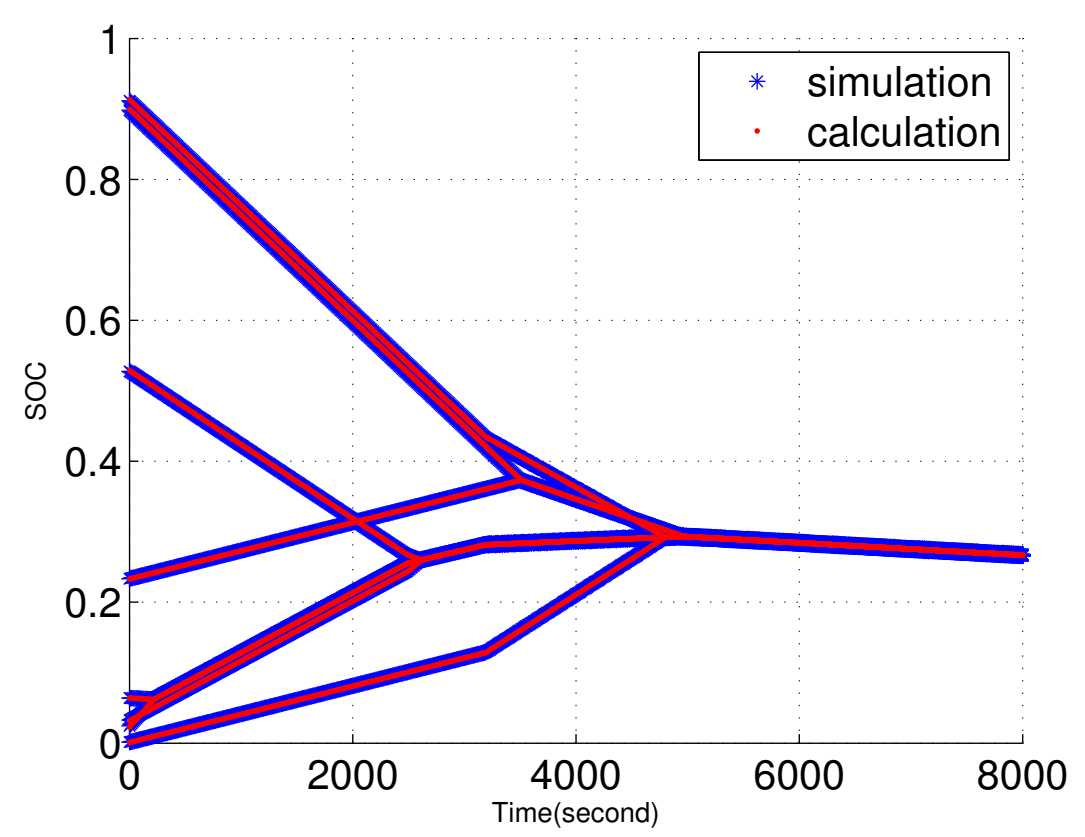

(b) Module-based system

Fig. 5.2: Battery equalization processes under two structures in Example 2. (a) Layerbased equalization. (b) Module-based equalization 


\subsection{Comparison of different equalization rate}

In addition, we compare the equalization time of changing some equalizers' equalization rate in layer and module structure. The results are shown in the table below.

Table 5.9: Average equalization time in layer structure changing equalization rate in one layer $(\mathrm{B}=8)$

\begin{tabular}{|l|l|l|l|l|}
\hline$r_{h}=10^{-4}$ & $r_{h}=10^{-4}(h \neq 1)$ & $r_{h}=10^{-4}(h \neq 2)$ & $r_{h}=10^{-4}(h \neq 3)$ & $r_{h}=1.5 \cdot 10^{-4}$ \\
$h=1 \ldots 3$ & $r_{1}=1.5 \cdot 10^{-4}$ & $r_{2}=1.5 \cdot 10^{-4}$ & $r_{3}=1.5 \cdot 10^{-4}$ & $h=1 \ldots 3$ \\
\hline 5094 & 4840 & 4622 & 4474 & 3396 \\
\hline
\end{tabular}

Table 5.10: Average equalization time in layer structure changing equalization rate in one layer $(\mathrm{B}=16)$

\begin{tabular}{|l|l|l|l|l|l|}
\hline$r_{h}=10^{-4}$ & $r_{h}=10^{-4}$ & $r_{h}=10^{-4}$ & $r_{h}=10^{-4}$ & $r_{h}=10^{-4}$ & $r_{h}=1.5 \cdot 10^{-4}$ \\
$h=1 \ldots 4$ & $(h \neq 1)$ & $(h \neq 2)$ & $(h \neq 3)$ & $(h \neq 4)$ & $h=1 \ldots 4$ \\
& $r_{1}=1.5 \cdot 10^{-4}$ & $r_{2}=1.5 \cdot 10^{-4}$ & $r_{3}=1.5 \cdot 10^{-4}$ & $r_{4}=1.5 \cdot 10^{-4}$ & \\
\hline 7241 & 7186 & 6932 & 6629 & 6398 & 4828 \\
\hline
\end{tabular}

Table 5.9 to 5.12 are comparisons of equalization time changing the equalization rate of equalizers in one layer for $B=8,16,32,64$ respectively. The new equalization rate is 1.5 times of the original one, which is $1.5 \cdot 10^{-4}$. From table 5.9 to 5.12 we can see that the equalization time is inversely proportional to the equalization rate of equalizers, that is when the equalization rate of all equalizers is 1.5 times of the original 
Table 5.11: Average equalization time in layer structure changing equalization rate in one layer $(\mathrm{B}=32)$

\begin{tabular}{|l|l|l|l|l|l|l|}
\hline$r_{h}=10^{-4}$ & $r_{h}=10^{-4}$ & $r_{h}=10^{-4}$ & $r_{h}=10^{-4}$ & $r_{h}=10^{-4}$ & $r_{h}=10^{-4}$ & $r_{h}=1.5 \cdot 10^{-4}$ \\
$h=1 \ldots 5$ & $(h \neq 1)$ & $(h \neq 2)$ & $(h \neq 3)$ & $(h \neq 4)$ & $(h \neq 5)$ & $h=1 \ldots 5$ \\
& $r_{1}=1.5 \cdot$ & $r_{2}=1.5 \cdot$ & $r_{3}=1.5 \cdot$ & $r_{4}=1.5 \cdot$ & $r_{5}=1.5 \cdot$ \\
10286 & $10^{-4}$ & $10^{-4}$ & $10^{-4}$ & $10^{-4}$ & $10^{-4}$ & \\
\hline & 10283 & 10173 & 9870 & 9454 & 9124 & 6857 \\
\hline
\end{tabular}

Table 5.12: Average equalization time in layer structure changing equalization rate in one layer $(\mathrm{B}=64)$

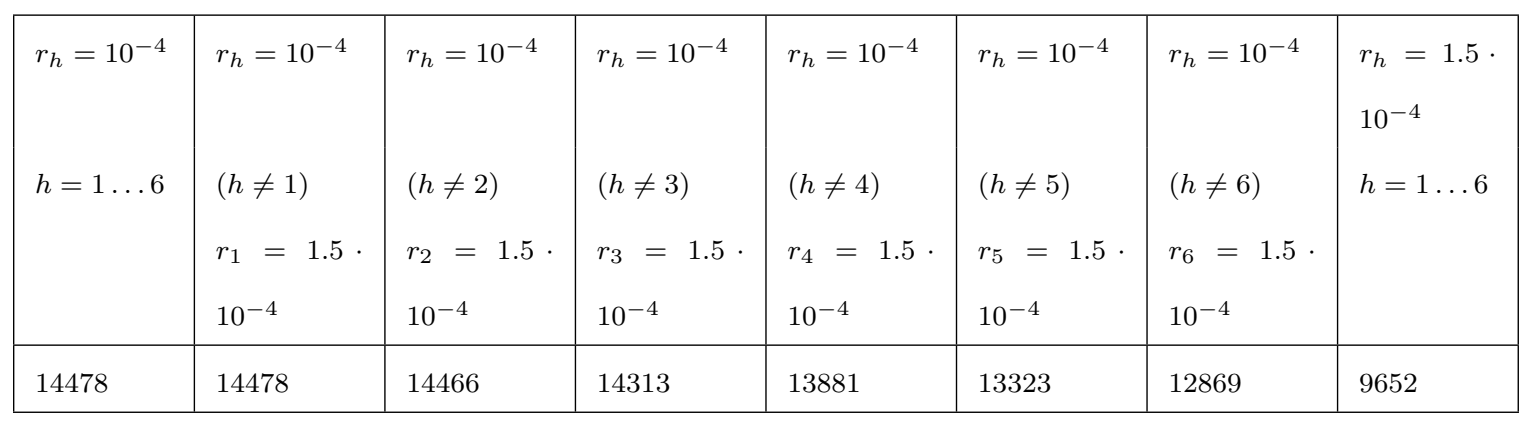


ones, the equalization time is $\frac{1}{1.5}$ times of the original equalization time. Also, increasing the largest layer's equalization rate lead to the best performance. What's more, the number of equalizers in layer $1,2, \ldots L$ is $B / 2, B / 4, \ldots 1$ respectively. So the largest layer have the smallest number of equalizer, which is 1 . Since increasing all equalizers' equalization rate sometimes is not reality in real applications, we should consider increasing the equalization rate of the equalizers in larger layer first.

We also compare the equalization time of module-based structure when only increasing cell level or module level equalizers' equalization rate. The results are shown below:

Table 5.13: Average equalization time in module structure with different equalization $\operatorname{rate}(\mathrm{B}=8)$

\begin{tabular}{|l|l|l|l|l|}
\hline & $r_{m}=r_{c}=10^{-4}$ & $r_{m}=10^{-4}$ & $r_{m}=1.5 \cdot 10^{-4}$ & $r_{m}=r_{c}=1.5 \cdot 10^{-4}$ \\
& & $r_{c}=1.5 \cdot 10^{-4}$ & $r_{c}=10^{-4}$ & \\
\hline$b=2$ & 5303 & 5064 & 4009 & 3535 \\
\hline$b=4$ & 5242 & 4317 & 4660 & 3495 \\
\hline
\end{tabular}

From Tables 5.13 to 5.16 we can see that the same as layer-based structure, the equalization time is inversely proportion to the equalization rate of equalizers, that is when the equalization rate of all equalizers is 1.5 times of the original ones, the equalization time is $\frac{1}{1.5}$ times of the original equalization time. Also, the performance of improving the equalization rate of cell-level equalizers or module-level equalizers 
Table 5.14: Average equalization time in module structure with different equalization $\operatorname{rate}(\mathrm{B}=16)$

\begin{tabular}{|l|l|l|l|l|}
\hline & $r_{m}=r_{c}=10^{-4}$ & $r_{m}=10^{-4}$ & $r_{m}=1.5 \cdot 10^{-4}$ & $r_{m}=r_{c}=1.5 \cdot 10^{-4}$ \\
& & $r_{c}=1.5 \cdot 10^{-4}$ & $r_{c}=10^{-4}$ & \\
\hline$b=2$ & 8171 & 8131 & 5647 & 5448 \\
\hline$b=4$ & 7615 & 7164 & 5957 & 5007 \\
\hline$b=8$ & 7904 & 6340 & 7198 & 5269 \\
\hline
\end{tabular}

Table 5.15: Average equalization time in module structure with different equalization $\operatorname{rate}(\mathrm{B}=32)$

\begin{tabular}{|l|l|l|l|l|}
\hline & $r_{m}=r_{c}=10^{-4}$ & $\begin{array}{l}r_{m}=10^{-4} \\
r_{c}=1.5 \cdot 10^{-4}\end{array}$ & $\begin{array}{l}r_{m}=1.5 \cdot 10^{-4} \\
r_{c}=10^{-4}\end{array}$ & $r_{m}=r_{c}=1.5 \cdot 10^{-4}$ \\
\hline$b=2$ & 12520 & 12518 & 8375 & 8346 \\
\hline$b=4$ & 11561 & 11462 & 8117 & 7707 \\
\hline$b=8$ & 11078 & 10214 & 8971 & 7385 \\
\hline$b=16$ & 11744 & 9262 & 10876 & 7829 \\
\hline
\end{tabular}


Table 5.16: Average equalization time in module structure with different equalization $\operatorname{rate}(B=64)$

\begin{tabular}{|l|l|l|l|l|}
\hline & $r_{m}=r_{c}=10^{-4}$ & $r_{m}=10^{-4}$ & $r_{m}=1.5 \cdot 10^{-4}$ & $r_{m}=r_{c}=1.5 \cdot 10^{-4}$ \\
\hline$b=2$ & 18665 & $r_{c}=1.5 \cdot 10^{-4}$ & $r_{c}=10^{-4}$ & \\
\hline$b=4$ & 17603 & 18665 & 12444 & 12443 \\
\hline$b=8$ & 16417 & 16155 & 11820 & 11735 \\
\hline$b=16$ & 15962 & 14468 & 11820 & 10945 \\
\hline$b=32$ & 17089 & 13266 & 13252 & 10642 \\
\hline
\end{tabular}

depend on the cell number of each module. For example, when $B=16$, for the case that $b=2$ and $b=4$, improving the equalization rate of module-level equalizers performs better than improving the equalization rate of cell-level equalizers. However, for the case that $b=8$, improving the equalization rate of cell-level equalizers performs better instead. 


\section{Chapter 6}

\section{Conclusions and Future Work}

\subsection{Conclusion}

In this thesis, we study the layer- and module-based battery equalization systems with energy loss during the equalization process. Specifically, mathematical models are formulated to describe the system-level dynamics of the equalization process under the two equalization structures. Then, based on the mathematical models, we derive analytical formulas to calculate the total time needed to complete system equalization under given initial SOCs of the cells. In addition, algorithms are developed for quick calculation of the cell SOCs during the equalization process. The accuracy and computational efficiency of the proposed algorithms are justified using extensive numerical experiments. Then, the approach is extended to analyze the system with simultaneous equalization and charging/discharging. Finally, we discuss two specific example that the different initial SOC would affect the total equalization time of the battery system for different structures. Also, we use numerous test to compare the effectiveness of the series-, layer- and module-based battery equalization structure. As a result, both layer- 
and module-based structures result in shorter equalization time on average. Especially, the superiority of the layer-based structure becomes more significant for systems with a large number of batteries. Note that the layer-based structure provides the best average efficiency since it has the shortest equalization time, which result in less loss of energy. Thus, we can conclude that, in a systematic perspective, the layer-based equalization structure on average performance better than both series-based and module-based structures under different circumstances. Also, for layer-based structure, we change the equalization rate of the equalizers in the same layer and get the conclusion that the improvement of the equalization rate of equalizers in the highest layer result in the best performance; for module-based structure, we compare changing the equalization rate of equalizers in the module-level and cell-level.

\subsection{Future Work}

In terms of the real battery systems, there are much more components within the system then what we have studied in this research. Thus a direction of the future work could be introducing more components to the model and make it more similar to the real circuit. For example, in this research, for layer-based structure, equalizers in the same layer have identical equalization rate; for module-based structure, all module-level equalizers have identical equalization rate, so are all cell-level equalizers. However, in order to achieve a better efficiency, the equalization rate of each individual equalizer could be controlled by some decision methods based on system's feedback. Under this direction, 
the future work includes:

- investigation these equalizations with different or time-varying equalization rate;

- investigation of these battery equalization systems with feedback control;

- extending the analysis to battery systems with other equalization structures. 


\section{Bibliography}

[1] J. Yan, Z. Cheng, G. Xu, H. Qian, and Y. Xu, "Fuzzy control for battery equalization based on state of charge," in Vehicular Technology Conference Fall (VTC 2010-Fall), 2010 IEEE 72nd. IEEE, 2010, pp. 1-7.

[2] J. Kim, J. Shin, C. Chun, and B. Cho, "Stable configuration of a li-ion series battery pack based on a screening process for improved voltage/soc balancing," Power Electronics, IEEE Transactions on, vol. 27, no. 1, pp. 411-424, 2012.

[3] Y.-S. Lee and G.-T. Cheng, "Quasi-resonant zero-current-switching bidirectional converter for battery equalization applications," Power Electronics, IEEE Transactions on, vol. 21, no. 5, pp. 1213-1224, 2006.

[4] A. Khaligh and Z. Li, "Battery, ultracapacitor, fuel cell, and hybrid energy storage systems for electric, hybrid electric, fuel cell, and plug-in hybrid electric vehicles: State of the art," Vehicular Technology, IEEE Transactions on, vol. 59, no. 6, pp. 2806-2814, 2010.

[5] Y.-S. Lee and G.-T. Chen, "Zcs bi-directional dc-to-dc converter application in battery equalization for electric vehicles," in Power Electronics Specialists Conference, 2004. PESC 04. 2004 IEEE 35th Annual, vol. 4. IEEE, 2004, pp. 27662772.

[6] D. Brunner, A. K. Prasad, S. G. Advani, and B. W. Peticolas, "A robust cell voltage monitoring system for analysis and diagnosis of fuel cell or battery systems," Journal of Power Sources, vol. 195, no. 24, pp. 8006-8012, 2010.

[7] W. Bentley, "Cell balancing considerations for lithium-ion battery systems," in Battery Conference on Applications and Advances, 1997., Twelfth Annual. IEEE, 1997, pp. 223-226.

[8] J. Cao, N. Schofield, and A. Emadi, "Battery balancing methods: A comprehensive review," in Vehicle Power and Propulsion Conference, 2008. VPPC'08. IEEE. IEEE, 2008, pp. 1-6. 
[9] H.-S. Park, C.-H. Kim, K.-B. Park, G.-W. Moon, and J.-H. Lee, "Design of a charge equalizer based on battery modularization," Vehicular Technology, IEEE Transactions on, vol. 58, no. 7, pp. 3216-3223, 2009.

[10] S. W. Moore and P. J. Schneider, "A review of cell equalization methods for lithium ion and lithium polymer battery systems," SAE Publication, vol. 2001010959, 2001.

[11] E. D. Sexton, R. F. Nelson, and J. B. Olson, "Improved charge algorithms for valve regulated lead acid batteries," in Battery Conference on Applications and Advances, 2000. The Fifteenth Annual. IEEE, 2000, pp. 211-216.

[12] W. Han, L. Zhang, and Y. Han, "Computationally efficient methods for state of charge approximation and performance measure calculation in series-connected battery equalization systems," Journal of Power Sources, vol. 286, pp. 145-158, 2015.

[13] B. Lindemark, "Individual cell voltage equalizers (ice) for reliable battery performance," in Telecommunications Energy Conference, 1991. INTELEC'91., 13th International. IEEE, 1991, pp. 196-201.

[14] G. L. Brainard, “Non-dissipative battery charger equalizer," Dec. 26 1995, uS Patent 5,479,083.

[15] A. Xu, S. Xie, and X. Liu, "Dynamic voltage equalization for series-connected ultracapacitors in ev/hev applications," Vehicular Technology, IEEE Transactions on, vol. 58, no. 8, pp. 3981-3987, 2009.

[16] J. W. Kimball and P. T. Krein, "Analysis and design of switched capacitor converters," 2005.

[17] A. C. Baughman and M. Ferdowsi, "Double-tiered switched-capacitor battery charge equalization technique," Industrial Electronics, IEEE Transactions on, vol. 55, no. 6, pp. 2277-2285, 2008.

[18] Y. Yuanmao, K. Cheng, and Y. Yeung, "Zero-current switching switchedcapacitor zero-voltage-gap automatic equalization system for series battery string," Power Electronics, IEEE Transactions on, vol. 27, no. 7, pp. 3234-3242, 2012.

[19] N. H. Kutkut, H. L. Wiegman, D. M. Divan, and D. W. Novotny, "Design considerations for charge equalization of an electric vehicle battery system," Industry Applications, IEEE Transactions on, vol. 35, no. 1, pp. 28-35, 1999. 
[20] C.-H. Kim, M.-Y. Kim, H.-S. Park, and G.-W. Moon, “A modularized two-stage charge equalizer with cell selection switches for series-connected lithium-ion battery string in an hev," Power Electronics, IEEE Transactions on, vol. 27, no. 8, pp. 3764-3774, 2012.

[21] M. Daowd, N. Omar, P. Van Den Bossche, and J. Van Mierlo, "A review of passive and active battery balancing based on matlab/simulink," J. Int. Rev. Electr. Eng, vol. 6, pp. 2974-2989, 2011.

[22] W. C. Lee, D. Drury, and P. Mellor, "Comparison of passive cell balancing and active cell balancing for automotive batteries," in Vehicle Power and Propulsion Conference (VPPC), 2011 IEEE. IEEE, 2011, pp. 1-7.

[23] K. Sooksood, T. Stieglitz, and M. Ortmanns, "An active approach for charge balancing in functional electrical stimulation," Biomedical Circuits and Systems, IEEE Transactions on, vol. 4, no. 3, pp. 162-170, 2010.

[24] M. Einhorn, W. Roessler, and J. Fleig, "Improved performance of serially connected li-ion batteries with active cell balancing in electric vehicles," Vehicular Technology, IEEE Transactions on, vol. 60, no. 6, pp. 2448-2457, 2011.

[25] D. V. Cadar, D. M. Petreus, and T. M. Patarau, "An energy converter method for battery cell balancing," in Electronics Technology (ISSE), 201033 rd International Spring Seminar on. IEEE, 2010, pp. 290-293.

[26] S. West and P. T. Krein, "Equalization of valve-regulated lead-acid batteries: issues and life test results," in Telecommunications Energy Conference, 2000. INTELEC. Twenty-second International. IEEE, 2000, pp. 439-446.

[27] P. T. Krein and R. S. Balog, "Life extension through charge equalization of leadacid batteries," in Telecommunications Energy Conference, 2002. INTELEC. 24th Annual International. IEEE, 2002, pp. 516-523.

[28] M. Daowd, N. Omar, P. Van Den Bossche, and J. Van Mierlo, "Passive and active battery balancing comparison based on matlab simulation," in Vehicle Power and Propulsion Conference (VPPC), 2011 IEEE. IEEE, 2011, pp. 1-7.

[29] Y. Zheng, M. Ouyang, L. Lu, J. Li, X. Han, and L. Xu, “On-line equalization for lithium-ion battery packs based on charging cell voltages: Part 1. equalization based on remaining charging capacity estimation," Journal of Power Sources, vol. 247, pp. 676-686, 2014.

[30] Y. Wang, C. Zhang, Z. Chen, J. Xie, and X. Zhang, "A novel active equalization method for lithium-ion batteries in electric vehicles," Applied Energy, vol. 145, pp. 36-42, 2015. 
[31] Y. Zheng, M. Ouyang, L. Lu, J. Li, X. Han, and L. Xu, "On-line equalization for lithium-ion battery packs based on charging cell voltages: Part 2. fuzzy logic equalization," Journal of Power Sources, vol. 247, pp. 460-466, 2014.

[32] A. Hande and T. Stuart, "A selective equalizer for nimh batteries," Journal of Power Sources, vol. 138, no. 1, pp. 327-339, 2004.

[33] L. Zhong, C. Zhang, Y. He, and Z. Chen, "A method for the estimation of the battery pack state of charge based on in-pack cells uniformity analysis," Applied Energy, vol. 113, pp. 558-564, 2014.

[34] S. Chen, C.-C. Chen, H.-P. Huang, and C.-C. Hwu, "Implementation of cell balancing with super-capacitor for robot power system," in Intelligent Control and Automation (WCICA), 2011 9th World Congress on. IEEE, 2011, pp. 468-473.

[35] D.-H. Zhang, G.-R. Zhu, S.-J. He, S. Qiu, Y. Ma, Q.-M. Wu, and W. Chen, "Balancing a control strategy for a li-ion batteries string based on the dynamic balanced point," Energies, vol. 8, no. 3, pp. 1830-1847, 2015.

[36] L.-R. Yu, Y.-C. Hsieh, W.-C. Liu, and C.-S. Moo, "Balanced discharging for serial battery power modules with boost converters," in System Science and Engineering (ICSSE), 2013 International Conference on. IEEE, 2013, pp. 449-453.

[37] J.-W. Kim, J.-W. Shin, and J.-I. Ha, "Cell balancing control using adjusted filters in flyback converter with single switch," in Energy Conversion Congress and Exposition (ECCE), 2013 IEEE. IEEE, 2013, pp. 287-291.

[38] Y. Guo, R. Lu, G. Wu, and C. Zhu, "A high efficiency isolated bidirectional equalizer for lithium-ion battery string," in Vehicle Power and Propulsion Conference (VPPC), 2012 IEEE. IEEE, 2012, pp. 962-966.

[39] C. S. Moo, Y. C. Hsieh, and I. Tsai, "Charge equalization for series-connected batteries," Aerospace and Electronic Systems, IEEE Transactions on, vol. 39, no. 2, pp. 704-710, 2003.

[40] Y.-S. Lee and M.-W. Cheng, "Intelligent control battery equalization for series connected lithium-ion battery strings," Industrial Electronics, IEEE Transactions on, vol. 52, no. 5, pp. 1297-1307, 2005.

[41] M. F. Samadi and M. Saif, "Nonlinear model predictive control for cell balancing in li-ion battery packs," in American Control Conference (ACC), 2014. IEEE, 2014, pp. 2924-2929.

[42] H. Chen, L. Zhang, and Y. Han, "System-theoretic analysis of a class of battery equalization systems: Mathematical modeling and performance evaluation," 2014. 